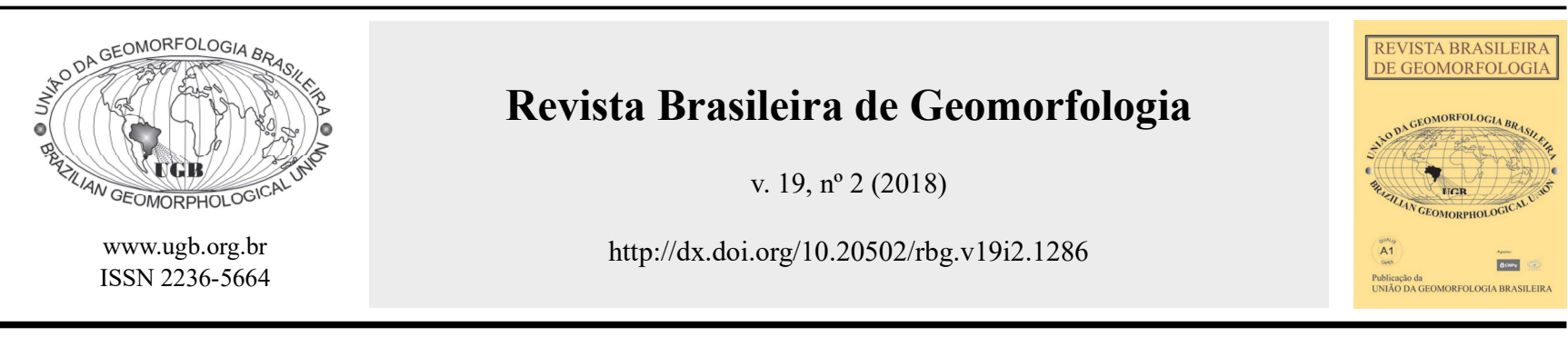

\title{
PROCESSOS DE FORMAÇÃO DE TERRENOS E RELEVOS TECNOGÊNICOS CORRELATIVOS À URBANIZAÇÃO: ANÁLISE MORFOESTRATIGRÁFICA E GEOAMBIENTAL APLICADA NA BACIA DO CÓRREGO ÁGUA BRANCA, ITAQUAQUECETUBA (RMSP)
}

\author{
TECHNOGENIC GROUND AND LANDFORMS FORMATION \\ PROCESSES CORRELATIVE TO URBANISATION: APPLIED \\ MORPHOSTRATIGRAPHIC AND GEO-ENVIRONMENTAL ANALYSIS IN \\ THE ÁGUA BRANCA STREAM BASIN, ITAQUAQUECETUBA (RMSP)
}

\author{
Alex Ubiratan Goossens Peloggia \\ Pesquisador Independente \\ Av.São Luís 71/304, São Paulo, São Paulo. CEP 01046-001. Brasil \\ Email: alexpeloggia@uol.com.br
}

Antonio Roberto Saad

Programa de Mestrado em Análise Geoambiental, Universidade Guarulhos Praça Teresa Cristina 88, Guarulhos, São Paulo. CEP 07020-071. Brasil

Email:saadhome@uol.com.br

Rodolfo Vieira da Silva

Programa de Mestrado em Análise Geoambiental, Universidade Guarulhos Praça Teresa Cristina 88, Guarulhos, São Paulo. CEP 07020-071. Brasil Email: prof.rodolfo@globo.com

William de Queiroz

Programa de Mestrado em Análise Geoambiental, Universidade Guarulhos Praça Teresa Cristina 88, Guarulhos, São Paulo. CEP 07020-071. Brasil

Email:wqguarulhos@gmail.com

Informações sobre o Artigo

Recebido (Received):

27/07/2017

Aceito (Accepted):

$15 / 12 / 2017$

\section{Palavras-chave:}

Terrenos Tecnogênicos; Análise de Bacias; Ocupação Urbana.

Keywords:

Technogenic Ground; Basin Analysis; Urban Occupation.

\section{Resumo:}

Este trabalho apresenta os resultados da análise morfoestratigráfica e geoambiental efetuada em uma sub-bacia de $3^{\mathrm{a}}$ ordem nas cabeceiras da bacia hidrográfica do córrego Água Branca, caracterizada como área de expansão urbana periférica na porção noroeste do município de Itaquaquecetuba, Região Metropolitana de São Paulo. A análise da bacia foi feita por critério topológico; a área foi dividida em topobacias de cabeceiras, correspondentes às áreas drenadas por canais de primeira ordem, e internas, referentes às áreas drenadas individualmente por segmentos fluviais de segunda e terceira ordem. Tal delimitação foi sobreposta à análise do uso e ocupação do solo, que se caracteriza no local pela diversidade de padrões de urbanização e pela ocorrência de áreas rurais remanescentes em processo de intensa transformação, assim como remanescentes de matas densas, originais 
ou secundárias. Realizou-se o mapeamento de detalhe dos terrenos tecnogênicos, observando a delimitação das áreas de degradação, submetidas a cortes ou processos erosivos, ou agradação (áreas de aterramento) e de terrenos complexos, classificando-os e identificando-se seus processos de formação.

\begin{abstract}
:
This paper presents the results of the morphostratigraphic and geo-environmental analysis carried out in a $3^{\text {rd }}$ order sub-basin in the headwaters of the Água Branca river basin, characterized as a peripheral urban expansion area in the northwest portion of the municipality of Itaquaquecetuba, Metropolitan Region of São Paulo. The analysis of the basin was made by topological criterion, dividing it into headwaters, corresponding to the areas drained by first order channels, and internal basins, referring to areas drained individually by second and third order fluvial segments. The analysis of land use and occupation, which is characterized in the locality by the diversity of urbanization patterns and by the occurrence of remaining rural areas in a process of intense transformation, as remnants of dense, original or secondary forests. A detailed mapping of the technogenic ground was carried out, observing the delimitation of degradation, subjected to cuts or erosion processes, or aggradation (landfilling) areas, and complex grounds, classifying them and identifying their formation processes.
\end{abstract}

\section{Introdução}

Na Região Metropolitana de São Paulo (RMSP), assim como em qualquer lugar onde o fenômeno da urbanização tenha se dado ou esteja se desenvolvendo, o ambiente geológico (ou meio físico) e as feições geomorfológicas originais do sítio urbano sofreram modificações que o reconfiguraram de forma intensa e extensiva, frequentemente implicando em impactos ambientais representados por processos de degradação significativos. No entanto, se tais consequências não são exatamente as mesmas em todas as áreas onde o processo de expansão urbana ocorreu ou ocorre, em termos de sua natureza, abrangência, causas e consequências, pode-se estabelecer, como regra geral, que sempre se associa a ele a formação de terrenos artificiais ou tecnogênicos, como atesta de modo abrangente a literatura (WATERS, 2018).

$\mathrm{Na}$ verdade, a relação entre a urbanização e a formação de terrenos e relevos tecnogênicos, em particular a formação de um "estrato geológico urbano" (ZALAZIEWICZ, 2008) ou uma "arqueosfera" (EDGEWORTH, 2014, 2015), já foi observada e descrita em textos clássicos por Suess (1862), para Viena, e Sherlock (1922), para Londres, e tem sido descrita em trabalhos recentes para outras cidades, como Moscou (ALEXANDROVSKAYA e ALEXANDROVSKIY, 2000), Tóquio (Kazuo, 2001), Swansea (WATERS et al., 2005), Presidente Prudente (SILVA et al. 2014), Volta Redonda (OLIVEIRA et al., 2015), Great Yarmouth (JORDAN et al., 2016) ou Pisa (BINI et al. 2017). No Reino Unido, o Serviço Geológico Britânico (BGS) tem mapeado sistematicamente, em escala 1:50.000, o artificial ground (PRICE et al., 2011), sendo os depósitos antropogênicos classificados em termos litoestratigráficos como Formações ou mesmo Grupos e Supergrupos (FORD et al., 2014).

No caso da RMSP, os primeiros trabalhos que descreveram ou registraram estratigraficamente as camadas tecnogênicas no sítio urbano tiveram início na década de 1990 (e.g. BARROS e PELOGGIA 1993, PELOGGIA, 1994, 1996, 1997a, 1997b, 1998, 1999a; KUTNER e BJORNBERG, 1997, FIGUEIRA 2007, OLIVEIRA et al., 2014, MIRANDOLA e AUGUSTO, 2014; VITORINO et al., 2016, BRAGA et al., 2016; SANTOS et al., 2017) concentrando-se, no entanto, na capital paulista e no município de Guarulhos. Nesse contexto, Peloggia $(1996,1998)$ propôs a denominação formação Várzea do Carmo para designar as camadas antropogênicas formadas no compartimento da antiga planície aluvial do rio Tamanduateí. Já os trabalhos mais detalhados referentes à transformação do relevo pela agência humana datam dos anos 1980 (ABREU, 1986, 1992), mas se desenvolveram mais significativamente a partir dos anos 2000 (e.g. RODRIGUES, 2004, 2005, 2010, 2015; PELOGGIA, 2005; LUZ, 2010, 2014; GOUVEIA, 2010; LUZ e RODRIGUES, 2013, 2015). Enfim, no Sudeste do Brasil, a urbanização corresponde, em termos geoambientais e geohistóricos, ao terceiro grande evento de transformação das paisagens regionais, seguindo-se ao Ciclo do Ouro do século XVIII e ao Ciclo do Café do século XIX (PELOGGIAe ORTEGA, 2016).

Na RMSP, embora de povoamento antigo, datando do século XVI, as áreas urbanas pouco se desenvolveram até os fins do século XIX, sendo o 
processo de expansão característico do século $\mathrm{XX}$, e ocorrendo aceleradamente em sua segunda metade, e repetindo um modelo básico de apropriação do relevo que, com poucas variações, é válido para a cidade de São Paulo e muitas de suas vizinhas, a saber: dos núcleos iniciais localizados em terrenos favoráveis, como os de colinas sustentadas por terrenos terciários, próximas às várzeas, a urbanização periférico-horizontal expande-se para as planícies fluviais adjacentes e, além delas, para terrenos de morros sustentados por maciços de alteração de rochas pré-cambrianas (PRADO, 1961a[1935], 1961b; AB'SABER 2007[1957], 1963a,b; ABREU, 1986, 1992; ROLNIK et al., 1991; PELOGGIA 1996, 1998; RICCA e PELOGGIA, 1997). Este processo também caracteriza a área estudada neste trabalho.

\section{Particularidade da área de estudo e método de análise}

A bacia hidrográfica estudada neste trabalho abrange uma área de $612 \mathrm{mil} \mathrm{m}^{2}$, e localiza-se nas cabeceiras de drenagem do córrego Água Branca, afluente da margem direita do rio Tietê, e contida inteiramente no território do município de Itaquaquecetuba, integrante da RMSP e posicionado a leste da capital (Figura 1). Trata-se de uma área de expansão urbana horizontal periférica em processo, onde se verificam padrões de ocupação diferenciados, desde bairros consolidados de classe média até assentamentos espontâneos precários e, ainda, áreas rurais remanescentes em processo de rápida transformação (Figura 2).

Tal área é interessante por dois motivos conjugados: primeiramente, por sua posição geomorfológica a montante da bacia do córrego Água Branca, o que implica a ocorrência de sub-bacias de primeira ordem com canais de maior declividade e vertentes em anfiteatros, reconhecidamente mais frágeis em termos geoambientais (FARIA e MARQUES, 1999); e, adicionalmente, em virtude de estar ocorrendo nessa bacia um processo de ocupação urbana rápido e diversificado. Destes fatores, resulta a particularidade da área como objeto de estudo, ou seja, a ocorrência, numa mesma bacia, de diversos tipos de interação entre processos de ocupação, formação de terrenos tecnogênicos e configurações geomorfológicas.

Neste contexto, a análise geoambiental proposta pautou-se: 1) no estudo bacia hidrográfica, por meio do método da análise topológica e da definição de topobacias unitárias (que não se confundem com o conceito de "ottobacias"); 2) na caracterização das diferentes formas de uso e ocupação do solo, ou seja, de apropriação do relevo, com base em observação de campo realizada em 2016 e 2017, análise de imagens de satélite, bem como de fotografias aéreas verticais e oblíquas obtidas por drone (modelo PHANTOM 4 WM330A GL300C) em março de 2017; 3) na identificação e análise dos processos tecnogênicos (movimentação de material geológico de forma direta ou indireta, e consequente criação de terrenos artificiais e suas formas de relevo associadas), com base em observações de campo e análise de fotografias aéreas do drone.

O mapeamento dos terrenos tecnogênicos foi realizado por critério morfoestratigráfico (morfogenético), ou seja, tomando como base as feições do relevo em associação à constituição litológica (HUGHES, 2010), abordagem que vem sendo utilizada, internacionalmente tendo como referência os trabalhos do Serviço Geológico Britânico (PRICE et al., 2011; FORD et al., 2014; BROWN et al., 2017; BINI et al., 2017), sendo aqui utilizada especificamente a classificação da geodiversidade tecnogênica proposta por Peloggia et al. (2014a,b), com aperfeiçoamentos posteriores (Vitorino et al., 2016; Peloggia, 2017). A representação cartográfica foi efetuada por tipos de terrenos tecnogênicos, de forma análoga ao realizado por Vitorino et al. (2016) para a bacia do Córrego do Entulho, em Guarulhos. O material cartográfico apresentado foi produzido no Laboratório de Geoprocessamento da Universidade Guarulhos, em ambiente SIG, com base em levantamento topográfico realizado pela CPRM - Serviço Geológico do Brasil, em 1:25.000, fornecido pela Prefeitura de Itaquaquecetuba.

\section{Análise da Bacia Hidrográfica}

A bacia hidrográfica considerada consiste em um sistema tecnogênico, entendido aqui como um espaço definido onde ocorre um conjunto articulado de movimentação e fluxo de materiais geológicos, envolvendo processos de erosão ou escavação, transporte, e deposição ou sedimentação, derivados das próprias formas de uso e ocupação do território, e nos quais a agência humana atua de forma direta ou indireta, com diferentes intensidades e impactos. Tratase de uma bacia drenada por uma rede fluvial de terceira ordem (conforme a classificação de SHTRALER, 1992), contendo um total de sete nascentes e canais de primeira ordem, apresentando padrão de drenagem dendrítico e forma triangular. 

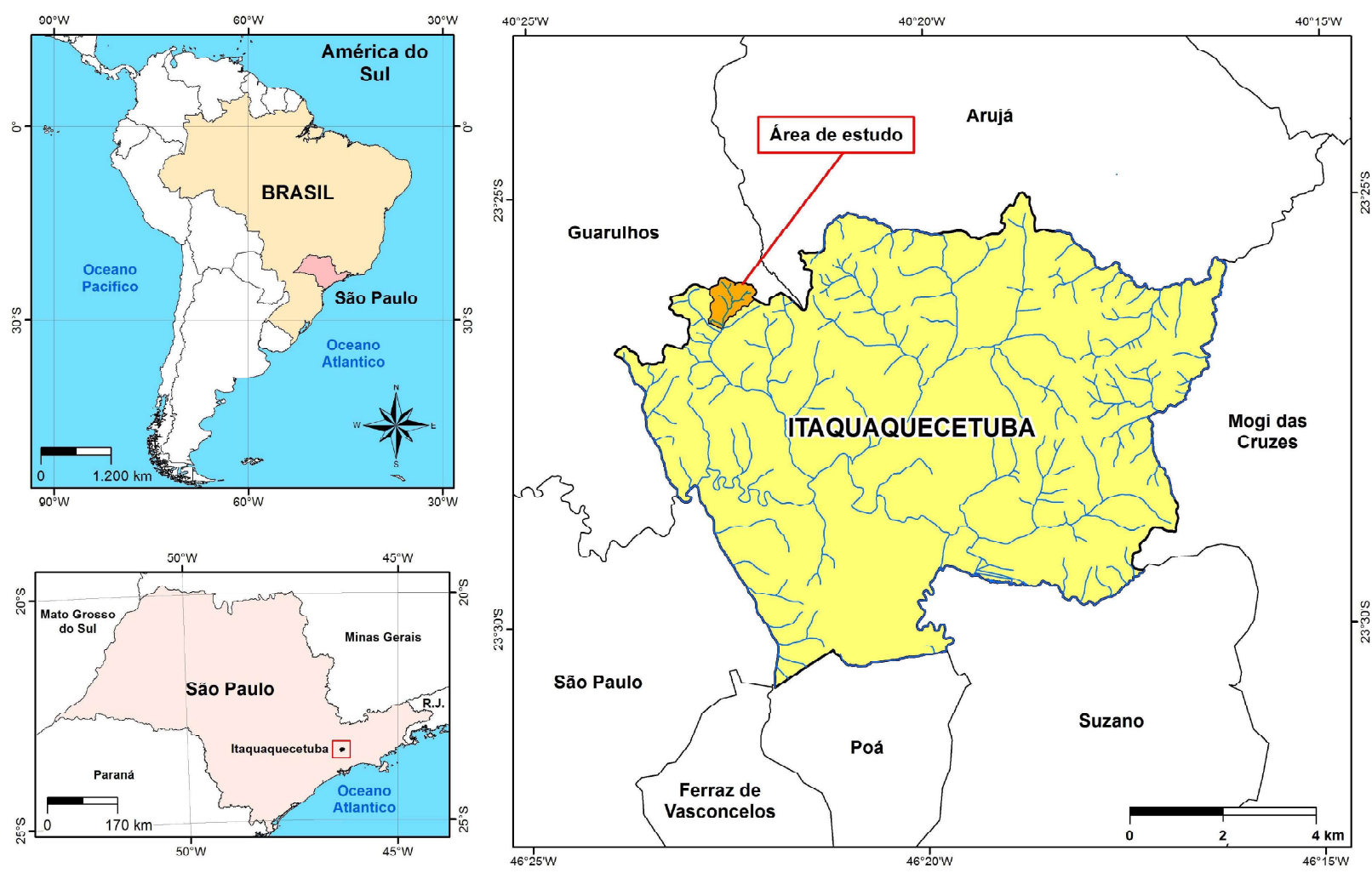

Figura 1 - Localização da área de estudo no contexto regional e da rede hidrográfica do município de Itaquaquecetuba.
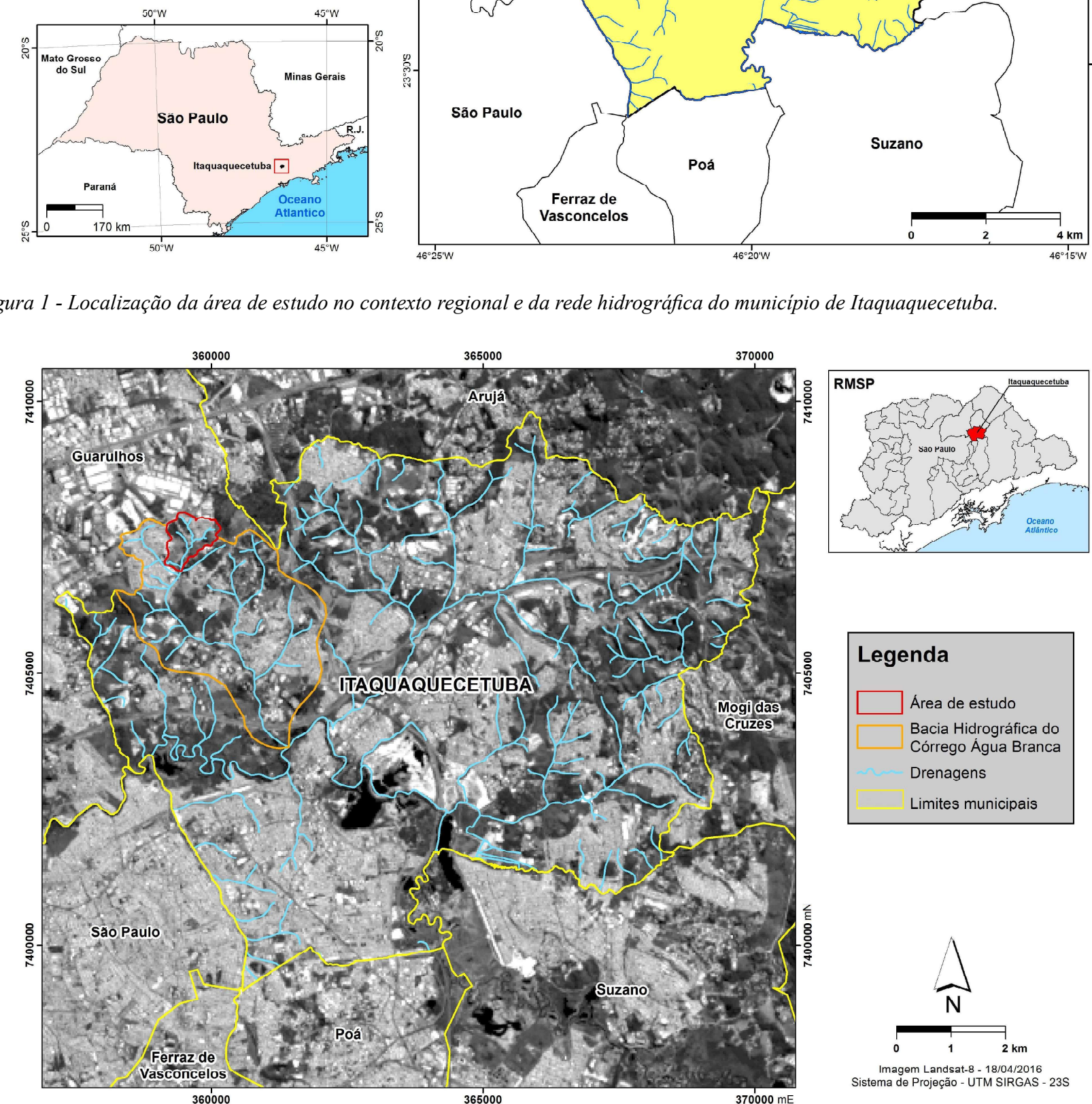

Figura 2 - Localização da área de estudo no contexto do município de Itaquaquecetuba e dos municípios vizinhos da Região Metropolitana de São Paulo. 
A compartimentação da bacia foi realizada a partir do método de análise topológica de redes fluviais, descrito por Christofoletti (1980), a partir de conceitos propostos por Horton (1945), Shreve (1966, 1967) e Scheidegger (1967). Em essência, o procedimento consiste em definir individualmente cada ligamento, ou seja, trechos do canal fluvial entre duas junções, ou ligamentos interiores, e entre uma junção e uma nascente, ou ligamentos exteriores. A seguir, os ligamentos são ordenados em sequência por meio de um caminhamento em sentido anti-horário, a partir da desembocadura, e utilizando-se uma combinação binária (dígito 0 para ligamentos interiores e dígito 1 para exteriores), sem repetição. Para a rede considerada, o resultado é: 0101001100111.
A partir da caracterização topológica binária da rede, considerou-se para cada ligamento fluvial sua respectiva área de drenagem, a partir da configuração topográfica, o que resultou na definição de treze bacias unitárias, ou topobacias, como se propõe aqui. Tomandose a sequência topológica, para cada bacia unitária interna (dígito 0 ) foi acrescido um dígito sequencial, iniciando-se pelo 1, o mesmo sendo realizado para as bacias externas ou de cabeceira de drenagem, correspondentes às bacias de $1^{\circ}$ ordem da classificação de Strahler. O resultado final do procedimento, ou seja, um código de dois algarismos para cada bacia, em que o primeiro indica e o segundo representa o ordenamento, como pode ser visto na figura 3, é o seguinte: $0.1-1.1-0.2-1.2-0.3-0.4-1.3-$ $1.4-0.5-0.6-1.5-1.6-1.7$.

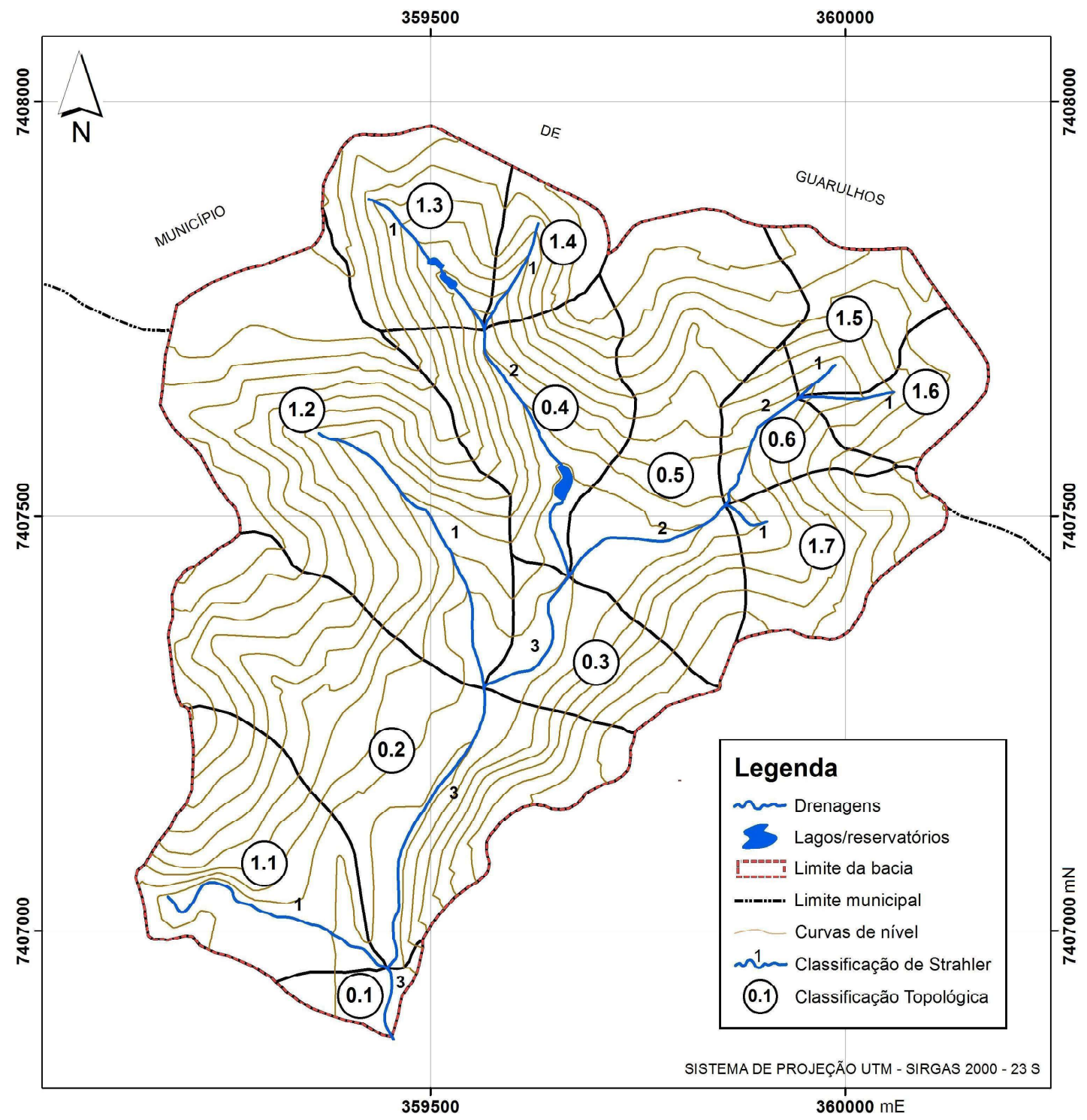

Figura 3 - Resultado da análise da bacia hidrográfica por critério topológico: o primeiro algarismo indica a posição externa ou de bacia de cabeceira (1) ou posição interna (2) das topobacias. 
Desse modo, cada uma das topobacias pode ser utilizada como unidade de referência para a caracterização do meio físico e a análise dos processos de uso e ocupação do solo, da tecnogênese, ou seja, da modificação do ambiente geológico pela ação humana com a formação de terrenos artificiais e suas formas de relevo associadas, e da degradação das condições ambientais.

\section{Configuração geológico-geomorfológica e carac- terísticas geotécnicas dos terrenos originais da bacia.}

Como lembra Ross (1996), os sistemas ambientais naturais, face às intervenções humanas, apresentam maior ou menor fragilidade em função de suas características genéticas. Desse modo, é conveniente verificar previamente as características do substrato geológico e do relevo sobre os quais os processos de formação de terrenos tecnogênicos têm ocorrido na bacia estudada. Os mapas geológicos de síntese disponíveis indicam a ocorrência, nas vertentes, de terrenos pré-cambrianos com predominância de migmatitos e gnaisses graníticos ou granodioríticos, eventualmente cisalhados em zonas de movimentação tectônica observados em escala 1:1000.000 (EMPLASA, 1980), estratigraficamente referidos ao Complexo Embu, unidade litoestratigráfica de idade Neoproterozóica (CPRM, 2005, em 1:750.000). Em campo, observam-se de fato biotita-gnaisses de aspecto porfiroide (Figura 4), mas também manchas restritas de sedimentos argilosos, possivelmente de idade terciária, em posição de pé de encosta. No fundo de vale, o mapa da Emplasa (1980) indica a ocorrência de sedimentos quaternários, sugerindo a ocorrência de uma planície aluvionar natural, embora não possa ser descartada, sem maiores investigações, a ocorrência de contribuição antropogênica na sedimentação, como antigos depósitos tecnogênico-sedimentares associados ao desmatamento original e uso agrícola do território.

Quanto ao relevo, o Mapa Geomorfológico do Estado de São Paulo do Instituto de Pesquisas Tecnológicas do Estado de São Paulo (IPT, 1981), em escala 1:1.000.000, insere a área em um relevo de morrotes baixos com topos arredondados, vertentes de perfis convexos a retilíneos e drenagem de alta densidade e planícies aluvionares restritas, o que de fato se verifica em campo. Já o Mapa Geomorfológico do Estado de São Paulo, de Ross e Moroz (1997), em escala 1:500.000, caracteriza o modelado da porção do município de Itaquaquecetuba, a norte do rio Tietê, como de morros altos e médios, apontando a ocorrência predominante de solos Podzólicos Vermelho-Amarelos (Argissolos Vermelho-Amarelos) e Cambissolos, indicando para o relevo da área um nível de fragilidade potencial muito alto, o que significa que, à ação humana que afete o equilíbrio geodinâmico eventualmente existente, corresponderão respostas morfogenéticas de intensidade significativa.

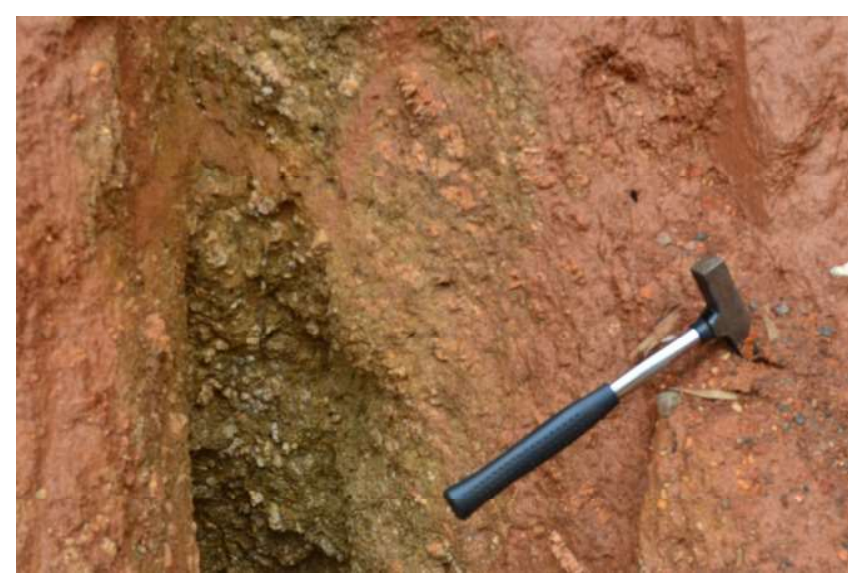

Figura 4 - Alterita (material de alteração ou saprolítico) de rocha metamórfica (gnaisse) preponderante no substrato das vertentes em toda a sub-bacia estudada.

Em termos geotécnicos, a Carta Geotécnica do Estado de São Paulo (IPT,1994), em escala 1:500.000, indica para a área da bacia estudada a ocorrência de terrenos com alta suscetibilidade à erosão nos solos superficiais, induzida por movimentos de terra, o que de fato se verifica em campo, mas para os solos de alteração de rocha, e secundariamente média suscetibilidade a movimentos de massa. Já a Carta de Suscetibilidade a Movimentos de Massa e Inundações, em escala 1:25.000 (IPT-CPRM, 2014), do município de Itaquaquecetuba, enquadra a maior parte da sub-bacia estudada na classe de suscetibilidade baixa a escorregamentos, com alguns setores restritos de suscetibilidade média, correspondentes às cabeceiras de drenagem das topobacias 1.2 (não ocupada) e 1.3 (ocupada).

\section{Uso do território e apropriação do relevo nas áreas de urbanização e suas franjas.}

A bacia estudada, até pelo menos o início da década de 1980, conforme pode ser verificado na Folha Itaquaquecetuba da carta geográfica em 1:50.000 
do IBGE (1984), apresentava predominantemente cobertura de mata, sem qualquer ocupação urbana. Já hoje ocorrem basicamente três grandes categorias de terrenos em termos urbanísticos do uso e ocupação do solo, a saber (Figuras 5 a 12):

Áreas urbanizadas, regulares, consolidadas, de padrão residencial horizontal de "classe média" (padrão "A"), que ocupa os topos convexos dos morros baixos, nos divisores de águas a norte e nordeste, nas porções topograficamente mais elevadas das topobacias 1.2 , $1.3,1.4,0.5$ e 1.5 .

Áreas em urbanização, ocupando as vertentes segundo dois padrões diferenciados: a leste (topobacias 1.1, 0.2 e 1.2), uma ocupação em lotes regulares, de autoconstrução, na média vertente (padrão "B"); e, a norte (topobacias 1.3, 1.4, 0.4, 0.5, 0.6, 1.5 e 1.6), uma ocupação de caráter irregular, espontâneo e precário (padrão “C"), em consolidação, porém ainda expandindose em áreas de remanescentes de mata ("D") e da ocupação do fundo de vale.

Áreas rurais remanescentes (padrão "E"), ocupando o fundo do vale de $3^{\mathrm{a}}$ ordem, a cabeceira de drenagem da topobacia 1.2 (fragmento de mata) e a vertente ESE da bacia da bacia (áreas de pasto e plantações, topobacias $0.1,1.1,0,2,0.3,0.5,0.6,1.6$ e 1.7$)$, em processo de rápida transformação de uso e intensa degradação ambiental.

É fundamental destacar que cada um desses tipos de uso ou padrões de ocupação produz interações diferenciadas com o sítio e seu substrato no decorrer do processo de apropriação do relevo, resultando na produção de diferentes terrenos artificiais. Portanto, pode-se relacionar diretamente a produção da geodiversidade tecnogênica à variabilidade da agência humana, esta que produz ações características que podem ser verificadas em contextos históricos e geográficos definidos, em função de condicionantes de natureza econômica, social e cultural particulares.

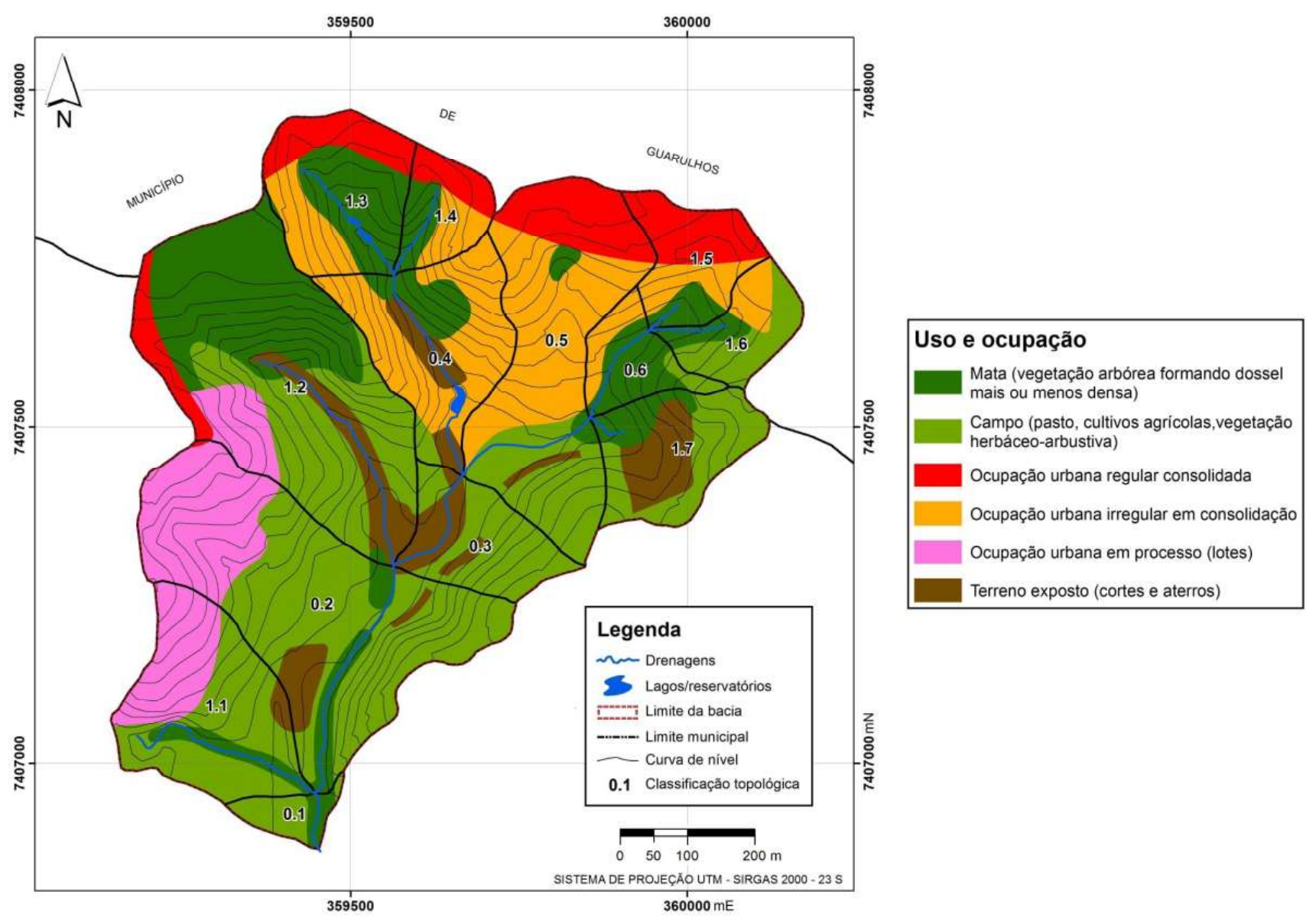

Figura 5 - Mapa de uso e ocupação do território, com indicação das topobacias. 


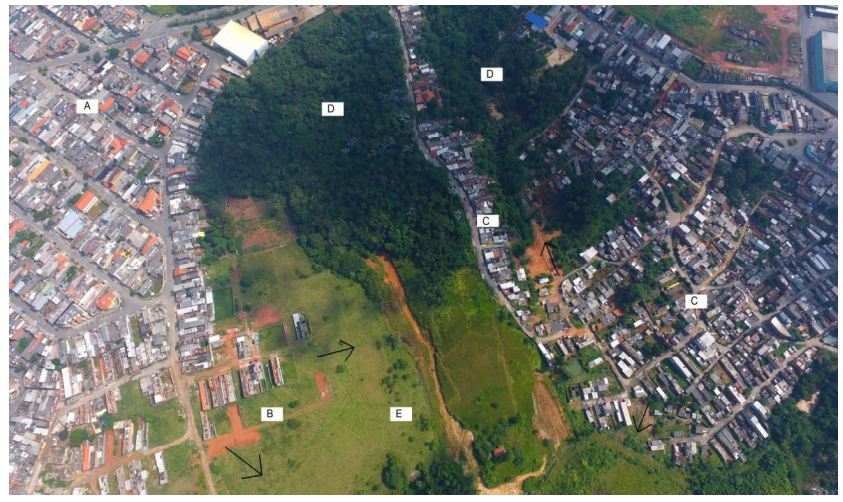

Figura 6 - Fotografia aérea subvertical realizada por drone (2017), mostrando: áreas de urbanização consolidada (A), urbanização em lotes em processo $(B)$ e urbanização precária em consolidação e expansão $(C)$, com fragmentos de mata remanescentes $(D)$ ou pasto (E) (topobacias 1.2, 0.4, 1.3 e 1.4). As setas indicam os sentidos de expansão da ocupação.

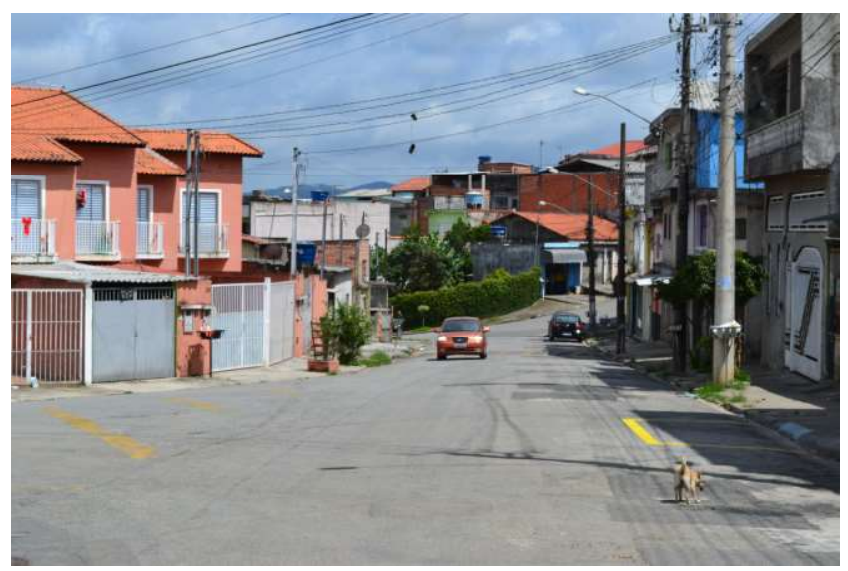

Figura 7 - Detalhe do padrão " $A$ " de ocupação regular consolidada dos topos dos morrotes.

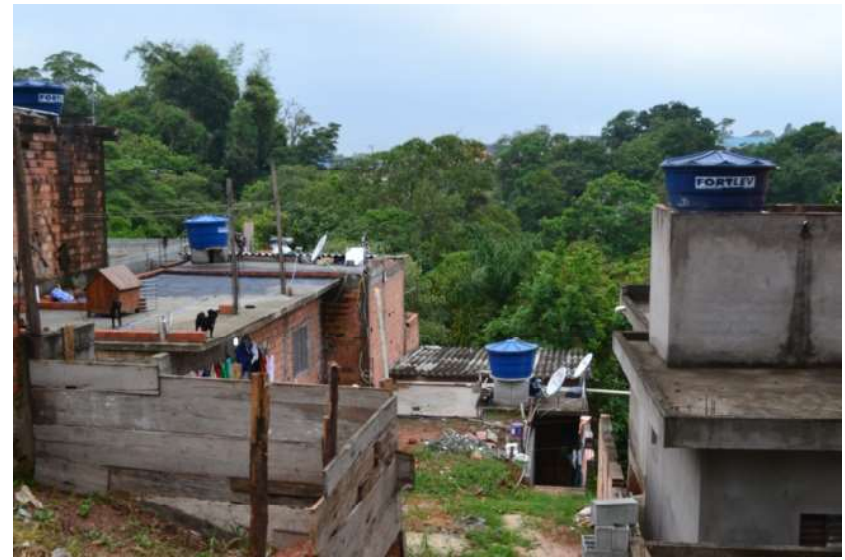

Figura 8 - Detalhe do padrão "C" de ocupação irregular precária, em expansão e consolidação.

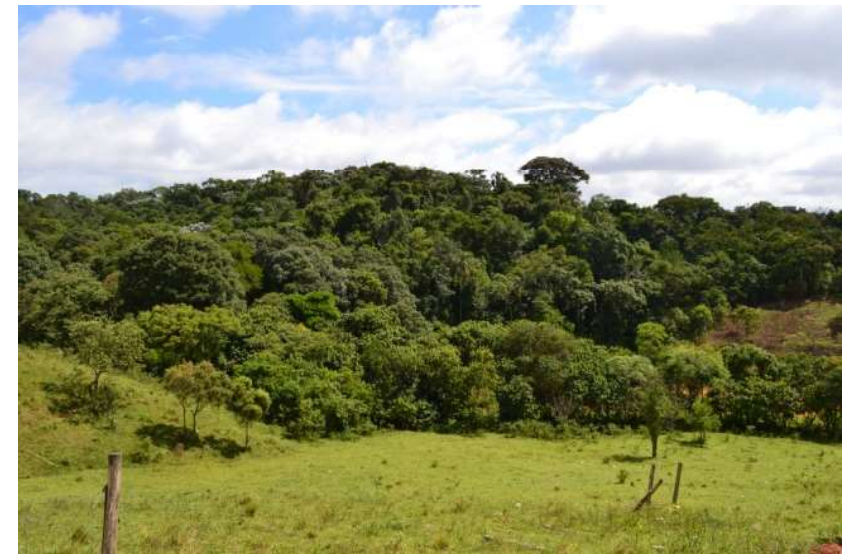

Figura 9 - Detalhe do fragmento de mata remanescente na cabeceira de drenagem da topobacia 1.2. (padrão "D")

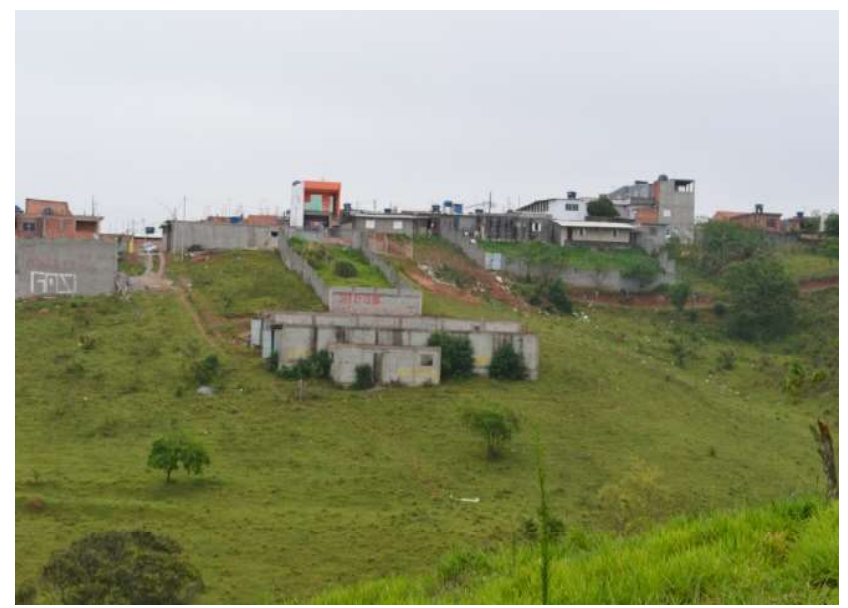

Figura 10 - Padrão "B” de ocupação em lotes, em expansão.

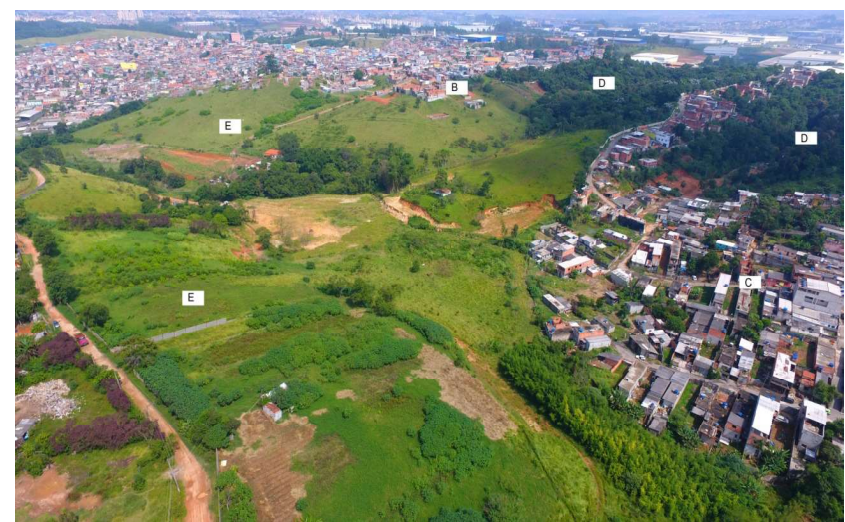

Figura 11 - Fotografia aérea obliqua (visão de $N$ para $S$ ) tomada por drone (março de 2017), mostrando o fundo do vale com áreas de plantação e pasto (E), fragmentos de mata remanescentes $(D)$, em contato com área de ocupação urbana precária $(C)$ 


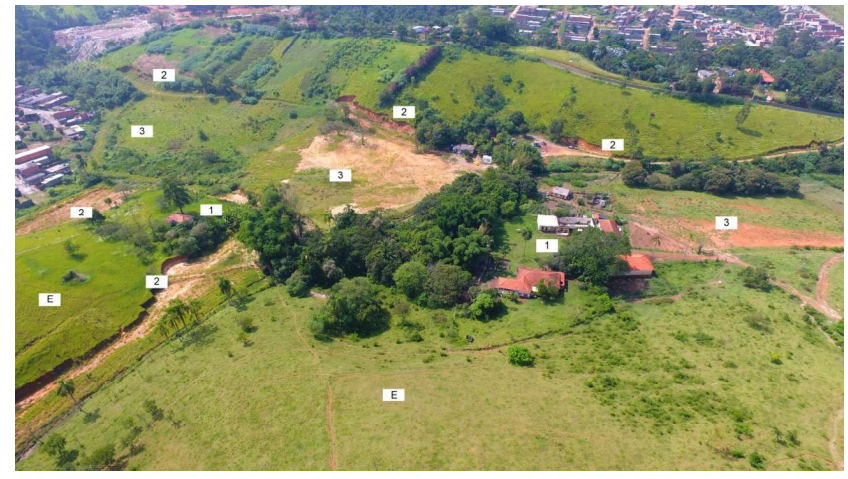

Figura 12 - Fotografia aérea oblíqua (vista de W para E) tomada por drone (março de 2017) mostrando remanescentes de construções rurais (1), campos cultivados e pastos (E) na porção central da bacia, juntamente com terrenos tecnogênicos de degradação (cortes) (2) e agradação (depósitos do fundo de vale) (3).

\section{Geodiversidade de terrenos tecnogênicos}

Os terrenos tecnogênicos ou artificiais, ou ainda antropogênicos, consistem em porções do território que foram transformados pela agência geológica humana, de forma direta ou indireta, por meio de processos de agradação - acumulação de material - ou degradação remoção de material -, que podem ocorrer conjugados de forma variada. Na área estudada, como resultado dessas ações, criou-se um cenário que, em conjunto, pode ser caracterizado como uma paisagem tecnogênica abrangente (PELOGGIA et al. 2014b), cujos terrenos são representados no mapa de terrenos (Figura 13) e indicados na figura 14, que mostram a geodiversidade tecnogênica classificada em classes de terrenos de agradação, degradação e complexos e seus respectivos tipos, de acordo com a proposta do Quadro 1.

A cada tipo de terreno tecnogênico mapeado correspondem formas de relevo particulares, de caráter agradativo ou degradativo (Quadro 2), o que evidencia o caráter morfoestratigráfico da classificação. Cada tipo de terreno de agradação, constituído por depósitos tecnogênicos, foi detalhado de acordo com a classificação integrada proposta por PELOGGIA(1999) associadamente à classificação faciológica (Quadro 3).

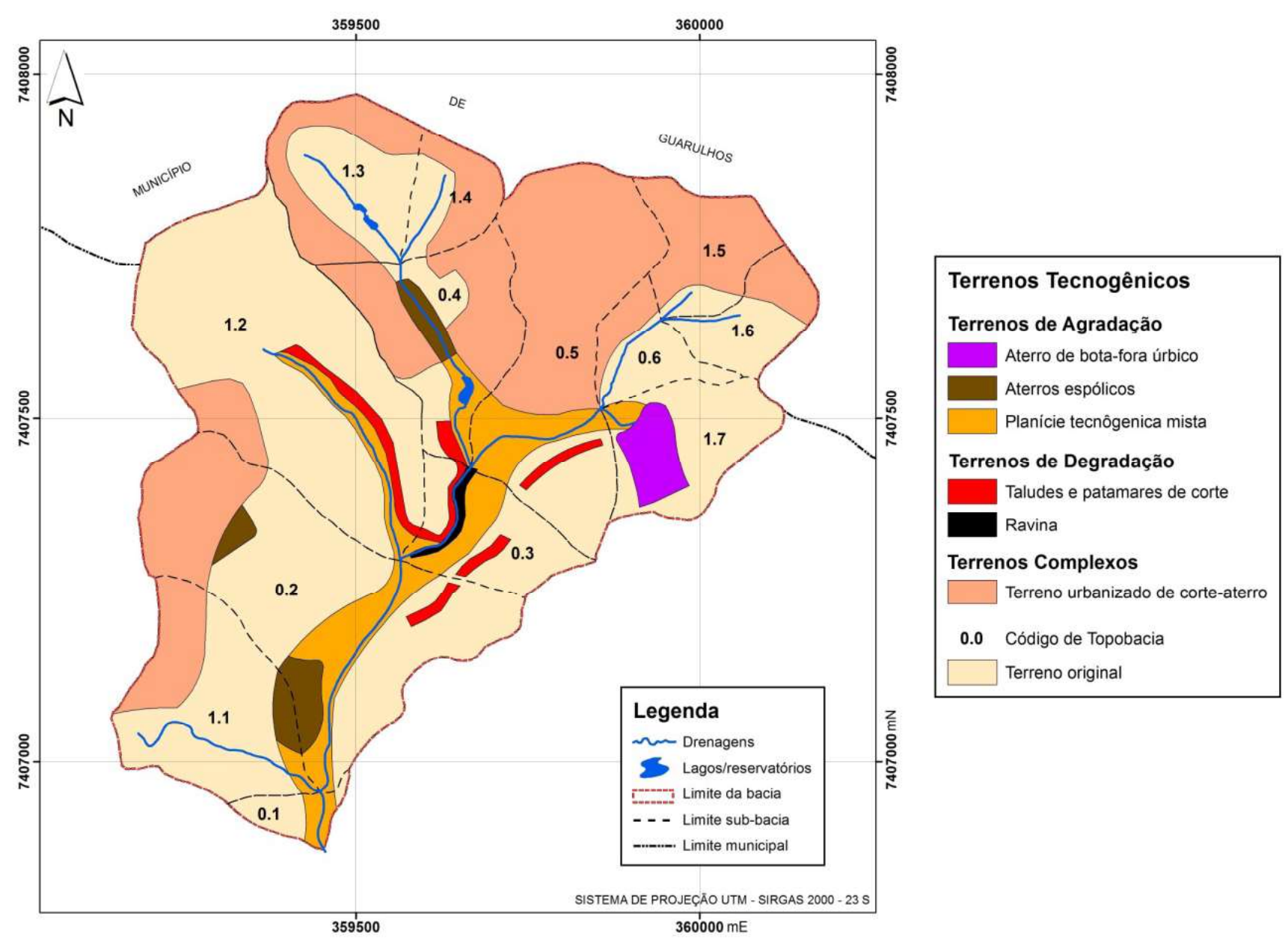

Figura 13 - Mapa de terrenos tecnogênicos (artificiais ou ainda antropogênicos) da bacia estudada. 


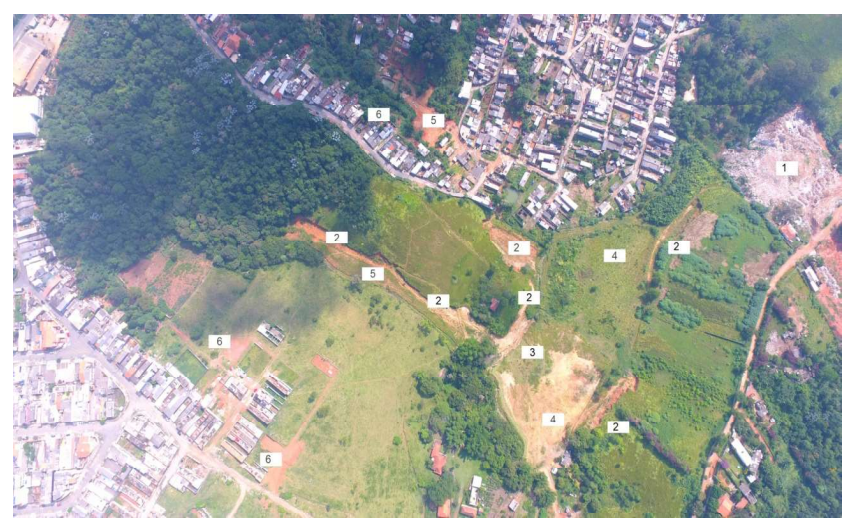

Figura 14 - Fotografia aérea subvertical adquirida por drone (março de 2017) da porção central da área estudada, onde podem ser visualizados os diferentes tipos de terrenos tecnogênicos formados: aterro de bota fora (1); cortes (2); ravina (3); planície tecnogênica (deposição induzida e aterros) (4); aterros (5); terrenos de corte e aterro (6).

\subsection{Terrenos tecnogênicos de degradação}

$\mathrm{Na}$ área ocorrem dois tipos diferenciados de terrenos de degradação: o primeiro, de produção direta, corresponde a taludes e patamares de corte efetuados com máquinas escavadoras e situados na base ou porção inferior das vertentes nas topobacias $1.2,0.3,0.4$ e 0.5 . (Figura 15). Os cortes expõem perfis geológicos constituídos por solo superficial relativamente pouco espesso, areno-argiloso, sobre alterita de rocha granitoide-gnáissica porfiróide, de textura areno-siltosa, muito micácea e francamente erodível. Os taludes resultantes são evidentemente instáveis, sendo observados processos de degradação induzidos generalizados como movimentos de massa e erosão linear (Figuras 16 e 17). O material escavado nas vertentes foi, em grande parte ou mesmo em totalidade, conforme observado em campo, utilizado para o aterramento do fundo do vale (Figura 18).

Quadro 1: Classificação de terrenos tecnogênicos para mapeamento geológico e geomorfológico.

\begin{tabular}{|c|c|c|c|c|c|}
\hline \multicolumn{6}{|c|}{ CLASSIFICAÇÃO DE TERRENOS TECNOGÊNICOS (ANTROPOGÊNICOS) PARA MAPEAMENTO GEOLÓGICO E GEOMORFOLÓGICO } \\
\hline CLASSE & Categori & eológica & & TIPO & CAMADA OU FEIÇÃO TECNOGÊNICA \\
\hline \multirow{8}{*}{$\begin{array}{l}\text { Terreno } \\
\text { Tecnogênico } \\
\text { de } \\
\text { Agradação }\end{array}$} & \multirow{10}{*}{$\begin{array}{l}\text { Formações } \\
\text { superficiais } \\
\text { antropogênicas }\end{array}$} & \multirow{8}{*}{$\begin{array}{l}\text { Depósitos } \\
\text { Tecnogênicos }\end{array}$} & \multirow{2}{*}{$\begin{array}{l}\text { Terreno } \\
\text { produzido } \\
\quad(1)\end{array}$} & Terreno aterrado & Depósitos tecnogênicos construídos \\
\hline & & & & Terreno acumulado & $\begin{array}{l}\text { Camadas tecnogênicas culturais (de ocupação, cons-trução ou } \\
\text { destruição) acumuladas sucessivamente. }\end{array}$ \\
\hline & & & \multicolumn{2}{|c|}{ Terreno preenchido (2) } & Depósitos tecnogênicos construídos recobrindo terreno escavado \\
\hline & & & \multirow{2}{*}{$\begin{array}{c}\text { Terreno } \\
\text { tecnogênico } \\
\text { sedimentar }\end{array}$} & Aluvial & Depósitos tecnogênicos induzidos de fundos de vale \\
\hline & & & & Coluvial & Depósitos tecnogênicos induzidos de vertentes \\
\hline & & & \multicolumn{2}{|c|}{ Terreno tecnogênico de escorregamento } & $\begin{array}{l}\text { Depósitos tecnogênicos induzidos criados por movimento de } \\
\text { massa }\end{array}$ \\
\hline & & & \multicolumn{2}{|c|}{ Terreno tecnogênico remobilizado } & $\begin{array}{l}\text { Depósitos tecnogênicos formados por remobi-lização de } \\
\text { depósitos tecnogênicos preexistentes }\end{array}$ \\
\hline & & & \multicolumn{2}{|c|}{ Terreno tecnogênico misto } & $\begin{array}{l}\text { Depósitos tecnogênicos construídos, induzidos ou remobilizados } \\
\text { formando pacote indiferenciado }\end{array}$ \\
\hline \multirow{2}{*}{$\begin{array}{l}\text { Terreno } \\
\text { Tecnogênico } \\
\text { Modificado }\end{array}$} & & \multirow{2}{*}{$\begin{array}{c}\text { Solos } \\
\text { Tecnogênicos }\end{array}$} & \multicolumn{2}{|c|}{ Terreno de composição alterada } & $\begin{array}{l}\text { Solos naturais com incorporação de contaminantes químicos ou } \\
\text { material orgânico }\end{array}$ \\
\hline & & & \multicolumn{2}{|c|}{ Terreno geomecanicamente alterado } & Solos naturais compactados ou revolvidos \\
\hline \multirow{4}{*}{$\begin{array}{c}\text { Terreno } \\
\text { tecnogênico } \\
\text { de } \\
\text { degradação }\end{array}$} & $\begin{array}{l}\text { Substrato } \\
\text { Exposto ou } \\
\text { Movimentado }\end{array}$ & & \multicolumn{2}{|r|}{ Terreno erodido } & Cicatrizes de erosão criadas por processos induzidos \\
\hline & & \multicolumn{2}{|c|}{ Terreno escorregado } & $\begin{array}{l}\text { Cicatrizes de } \\
\text { escorregamentos criadas } \\
\text { por processos induzidos }\end{array}$ & \\
\hline & & \multicolumn{2}{|c|}{$\begin{array}{l}\text { Terreno movimentado ou } \\
\quad \text { afundado (3) }\end{array}$} & $\begin{array}{l}\text { Depressões de subsidência } \\
\text { criadas por processos } \\
\text { induzidos }\end{array}$ & \\
\hline & & \multicolumn{2}{|c|}{ Terreno escavado (4) } & Superfícies de escavação & \\
\hline $\begin{array}{l}\text { Terreno } \\
\text { tecnogênico } \\
\text { complexo }\end{array}$ & \multicolumn{2}{|c|}{ Paisagem Tecnogênica } & \multicolumn{2}{|c|}{ Terreno complexo (5) } & $\begin{array}{l}\text { Terrenos formados pela agregação ou sobreposição complexa de } \\
\text { depósitos ou solos tecnogênicos ou superficies de exposição de } \\
\text { substrato, não diferenciáveis na escala de mapeamento adotada. }\end{array}$ \\
\hline
\end{tabular}

Fonte: Peloggia (2017), modificado de Peloggia et al. (2014a,b), Peloggia (2015) e Vitorino et al. (2016). As seguintes categorias provêm da classificação de terrenos artificiais do Serviço Geológico Britânico: (1) made ground; (2) infilled ground; (3) disturbed ground (4) worked ground; (5) landscaped ground. (McMillan e Powell, 1999; Rosembaum et al., 2003; Price et al., 2004; Price et al., 2011; Waters, 2018). 
Quadro 2: Classificação das formas de relevo tecnogênicas.

\begin{tabular}{|l|l|l|}
\hline \multicolumn{3}{|c|}{ FORMAS BÁSICAS DE RELEVO TECNOGÊNICAS } \\
\hline CATEGORIA & GÊNESE & TIPOS COMUNS \\
\hline Formas agradativas & $\begin{array}{l}\text { Superfícies geomórficas produzidas por processos de elevação } \\
\text { topográfica devido à acumulação de material, notadamente } \\
\text { aterramento, ou pela intensificação da deposição de sedimentos. }\end{array}$ & $\begin{array}{l}\text { (1) Formas deposicionais sedimentares. } \\
\text { (2) Aterros em geral. }\end{array}$ \\
\hline Formas degradativas & $\begin{array}{l}\text { Superfícies geomórficas produzidas ou modificadas pela remoção } \\
\text { de material geológico: diretamente por ação mecânica humana ou } \\
\text { indiretamente pela intensificação da erosão, ou mesmo pela erosão } \\
\text { natural agindo sobre depósitos tecnogênicos antigos. }\end{array}$ & $\begin{array}{l}\text { (1) Superfícies naturais que sofreram } \\
\text { processos de erosão acelerada } \\
\text { induzidos. } \\
\text { (2) Superfícies diretamente escavadas. }\end{array}$ \\
\hline Formas movimentadas & $\begin{array}{l}\text { Superfícies e sistemas geomórficos alterados topograficamente por } \\
\text { movimentação in situ de material geológico devido a processos } \\
\text { tecnogênicos superficiais ou subterrâneos. }\end{array}$ & $\begin{array}{l}\text { (1) Superfícies naturais que sofreram } \\
\text { processos de subsidência ou colapso. } \\
\text { (2) Padrões fluviais modificados. }\end{array}$ \\
\hline
\end{tabular}

Fonte: modificado de Peloggia et al. (2014b).

Quadro 3: Classificação faciológica de depósitos tecnogênicos

\begin{tabular}{|c|c|}
\hline \multicolumn{2}{|r|}{ CLASSIFICAÇÃO DE FÁCIES EM CAMADAS TECNOGÊNICAS } \\
\hline \multicolumn{2}{|c|}{$\begin{array}{l}\text { Regra de aplicação: a classificação faciológica do depósito resulta da conjunção do material constituinte com a estrutura: (A) } \\
+(B)\end{array}$} \\
\hline Tipo de material (A) & Composição do depósito \\
\hline Úrbico & $\begin{array}{l}\text { Materiais terrosos com artefatos (tecnofósseis), frequentemente em fragmentos, entulhos e detritos } \\
\text { urbanos em geral. }\end{array}$ \\
\hline Gárbico & Material detrítico com quantidade significativa de lixo orgânico. \\
\hline Espólico & $\begin{array}{l}\text { Material proveniente de escavação do manto de intemperismo, eventualmente com material rochoso } \\
\text { subordinado. }\end{array}$ \\
\hline Sedimentar & $\begin{array}{l}\text { Material sedimentar, frequentemente com clastos tecnogênicos de qualquer granulação, e } \\
\text { eventualmente tecnofósseis. }\end{array}$ \\
\hline Lítico & Material rochoso de granulação diversa, eventualmente com material terroso subordinado. \\
\hline Estrutura (B) & Características do modo de organização interna do depósito \\
\hline Estratificada & Estruturas resultantes de processos sedimentares. \\
\hline Acamadada & Sobreposições de camadas de características distintas ou não. \\
\hline Maciça & Material com distribuição e características homogêneas. \\
\hline Irregular & Arranjo aleatório de materiais de características distintas. \\
\hline Celular & Porções justapostas constituídas por materiais distintos. \\
\hline
\end{tabular}

Fonte: Peloggia (2017) e Vitorino et al. (2016), com base em Peloggia (1999) e Fanning e Fanning (1989).

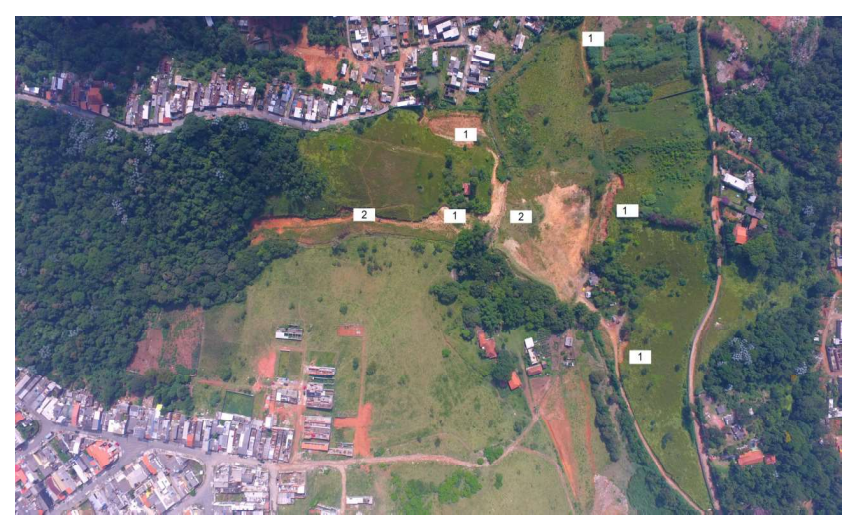

Figura 15 - Fotografia aérea subvertical obtida por drone (março de 2017), com vista de sul para norte, mostrando terrenos de degradação de corte (1) e erosão (2).

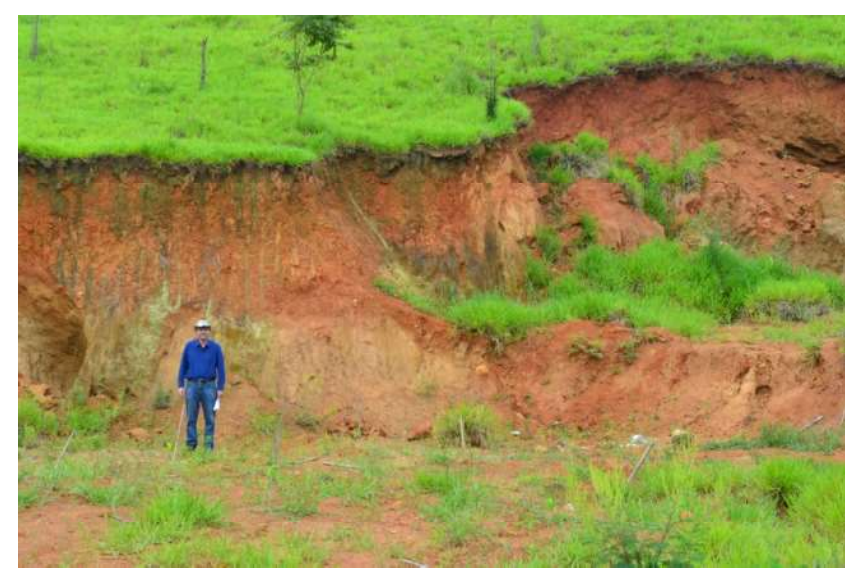

Figura 16 - Terreno de corte no sopé da encosta na topobacia 0.4, expondo alterita de gnaisse, com escorregamentos induzidos de tipo circular. 


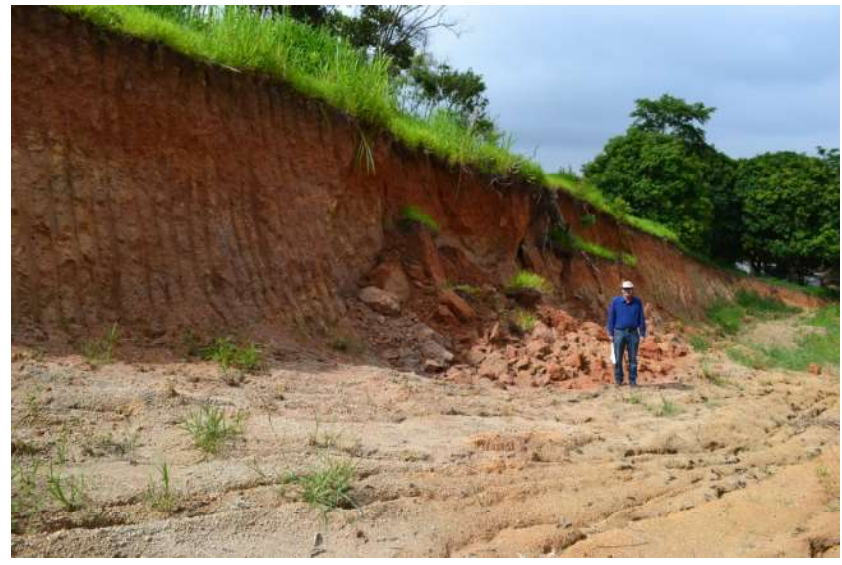

Figura 17 - Terreno de corte no sopé da encosta na topobacia 0.3, expondo alterita de gnaisse, com movimentos de massa (queda de blocos de material saprolitico) e erosão em sulcos.

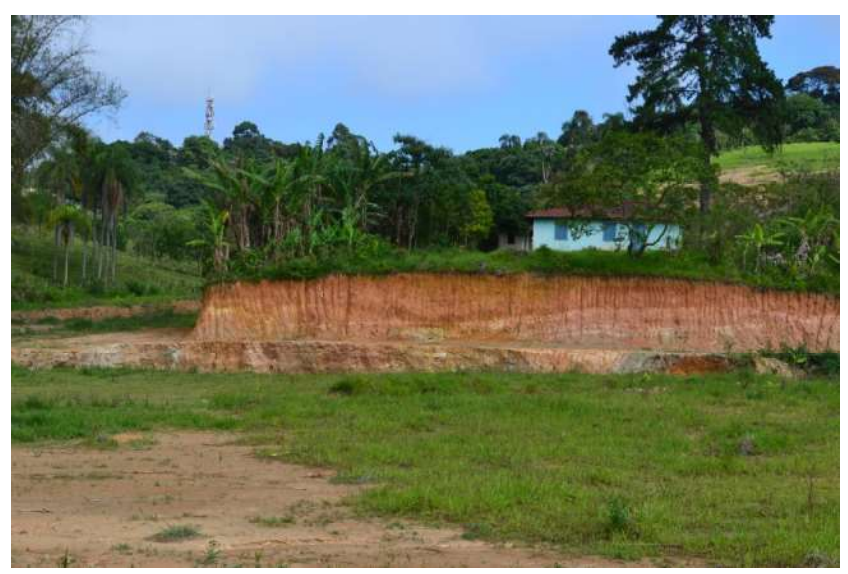

Figura 18 - Terreno de corte no sopé da encosta na topobacia 0.3, adjacente a edificação rural remanescente. Em primeiro plano estão os terrenos de agradação (depósitos) da planície tecnogênica.

O segundo terreno de degradação mapeado corresponde aos efeitos de um processo induzido de erosão acelerada, que resultou na formação de extensa ravina que escava o terreno constituído pelas alteritas descritas acima e por aterros do fundo de vale e antigos aluviões ou solos hidromórficos (Figura 19). O desencadeamento do fenômeno erosivo representa claramente um reajuste do canal de drenagem em função do desequilíbrio hidrodinâmico gerado pelo aterramento do fundo do vale, com resultante aumento do gradiente fluvial, associado à retificação do próprio canal de $3^{\text {a }}$ ordem.

A formação destes terrenos artificiais não corresponde diretamente aos processos de ocupação urbana do território da bacia, mas resulta de modificação proposital das porções de baixas vertentes e fundo de vale, em função da urbanização ocorrida ao redor e da mudança do uso do solo, anteriormente ocupadas por mata, uso agrícola ou de pastagem.

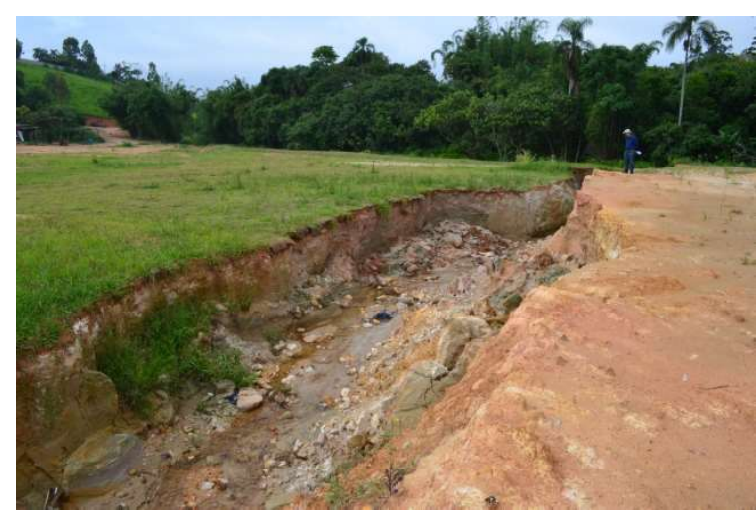

Figura 19 - Terreno de degradação caracterizado por extensa ravina decorrente de erosão acelerada no canal de $3^{a}$ ordem (topobacia $0.3)$.

\subsection{Terrenos tecnogênicos de agradação}

São identificados na bacia três tipos diferenciados de terrenos de agradação: depósitos de fundo de vale da planície tecnogênica, aterros espólicos de encosta e fundo de vale e aterro de bota-fora de encosta/cabeceira de drenagem (Figura 20).

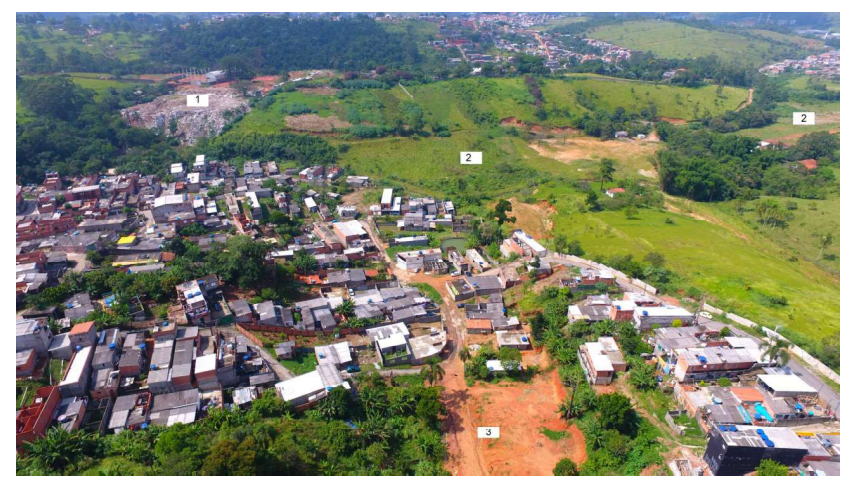

Figura 20 - Fotografia aérea oblíqua tomada por drone (março de 2017), com vista de W para E: aterro de bota-fora úrbico (topobacia 1.7) (1); depósitos de planície tecnogênica (topobacias 0.5, 0.3 e 0.2) (2); depósitos espólicos de fundo de vale (topobacia 0.4) (3).

\section{Aterro de bota-fora}

Trata-se de um depósito tecnogênico construído de encosta e cabeceira de drenagem, úrbico-maciço, periurbano, resultante do bota-fora irregular de material imprestável, como resíduos de demolições e restos de processos industriais, incluindo entulhos diversos, 
plásticos, restos de tecido, metal e madeira, sem quantidade significativa de material orgânico (Figura 21). O depósito foi acumulado pelo lançamento "em ponta", a partir do topo, o que resultou em taludes íngremes de até $45^{\circ}$ (portanto no limite da estabilidade geotécnica). Foram observadas evidências de que o material depositado sofreu combustão em alguns pontos (Figura 22).

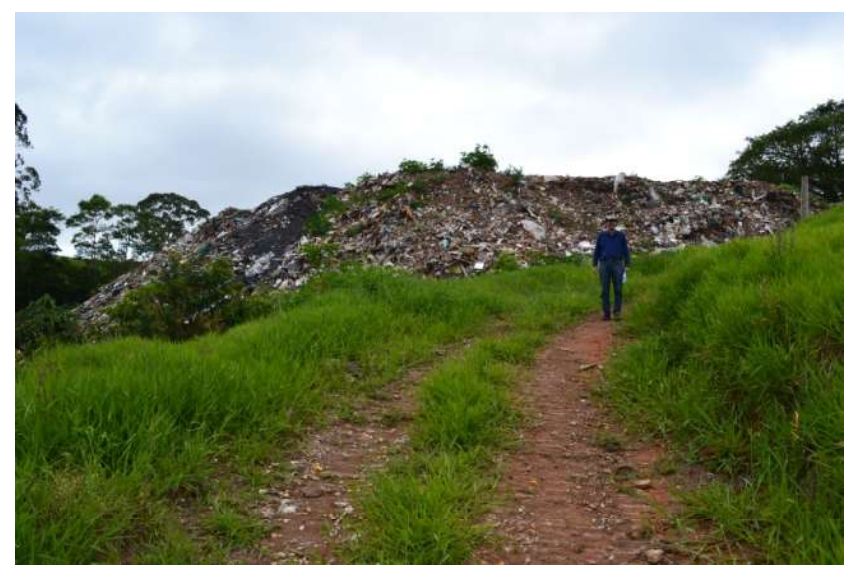

Figura 21 - Aterro de bota-fora úrbico-maciço, de encosta. Fica evidenciada a alta inclinação dos taludes resultante do lançamento "em ponta" do material.

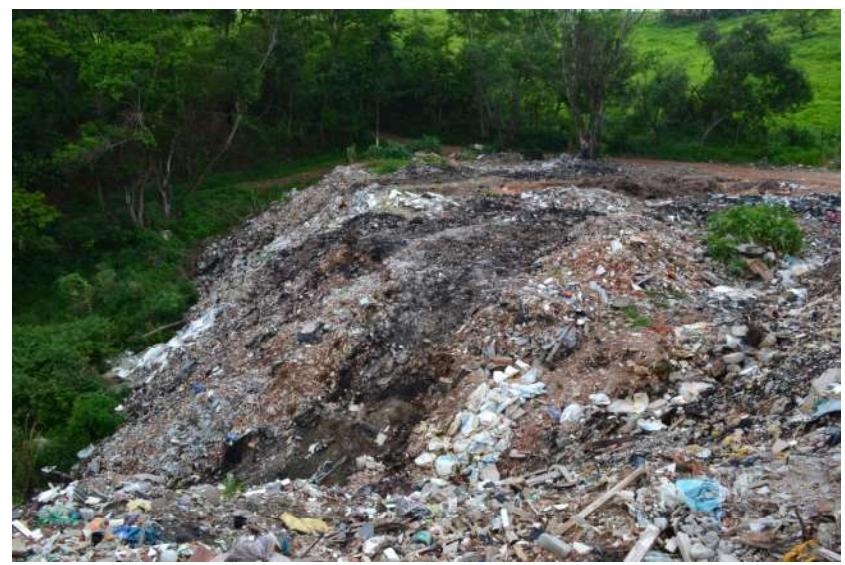

Figura 22 - Borda do aterro de bota-fora recobrindo a nascente da topobacia 1.7 .

\section{Aterros lançados}

São depósitos tecnogênicos construídos espólicomaciços, periurbanos ou rurais, de espessura variada de alguns decímetros a poucos metros, formados a partir do lançamento de material proveniente principalmente dos cortes efetuados na própria área, constituindo-se assim de material lançado "em ponta". A natureza do material original mobilizado, em geral uma alterita de gnaisse, silto-arenosa, associadamente à ausência de compactação, faz com que tais depósitos tenham péssimas características geotécnicas e sejam francamente erodíveis.

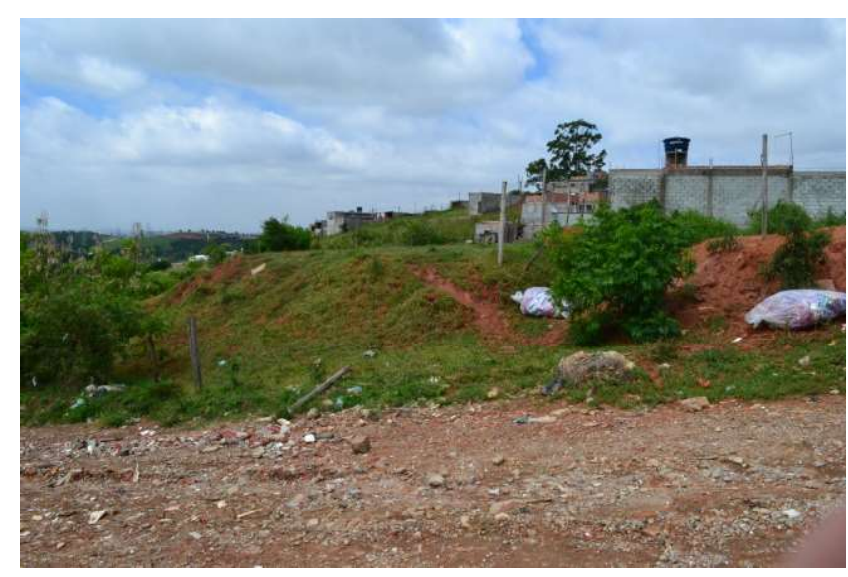

Figura 23 - Depósito tecnogênico contruido (aterro lançado) espólico-maciço de encosta, topobacia 0.2.

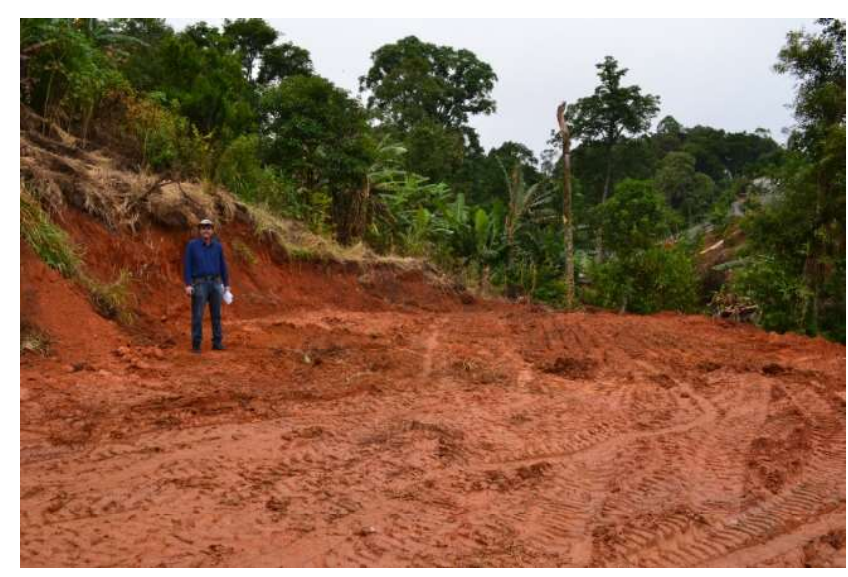

Figura 24 - Depósito tecnogênico (aterro lançado) espólico-maciço de fundo de vale, topobacia 0.4 .

\section{Planície tecnogênica}

A categoria geomorfológica "planície tecnogênica" foi proposta por Peloggia (1998) e utilizada por Peloggia et al. (2014b) para designar compartimentos de relevo produzidos pelo acúmulo de depósitos tecnogênicosedimentares induzidos ou construídos, o que resulta na sobreposição complexa de camadas (Figuras 25, 26 e 27). Na área, a planície se associa à porção mais larga do vale, correspondendo às porções de $3^{\mathrm{a}}$ ordem da rede de drenagem. Conquanto seja um terreno de agradação, a planície tecnogênica começa a sofrer remobilização do material depositado por erosão acelerada, com formação de ravinas extensas. 


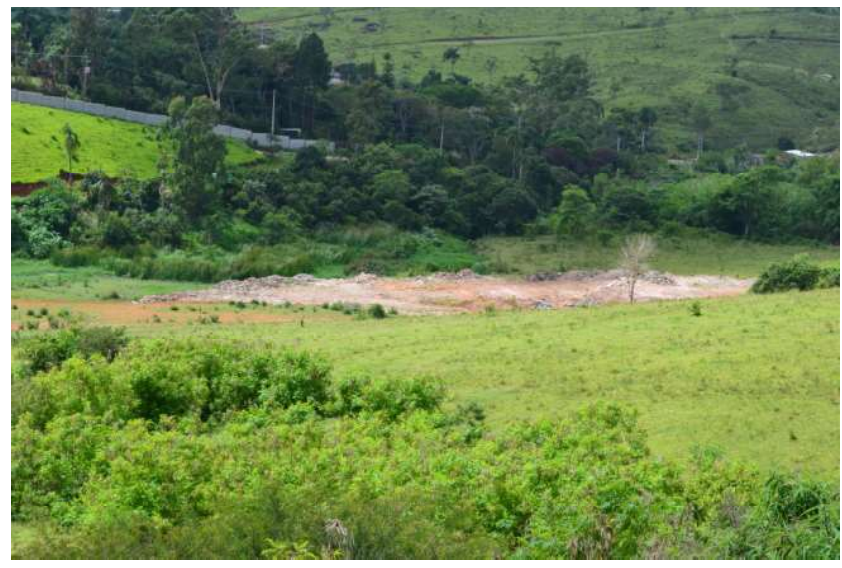

Figura 25 - Depósito tecnogênico (aterro) espólico-maciço depositado na planície tecnogênica (topobacias 1.1 e 0.2).

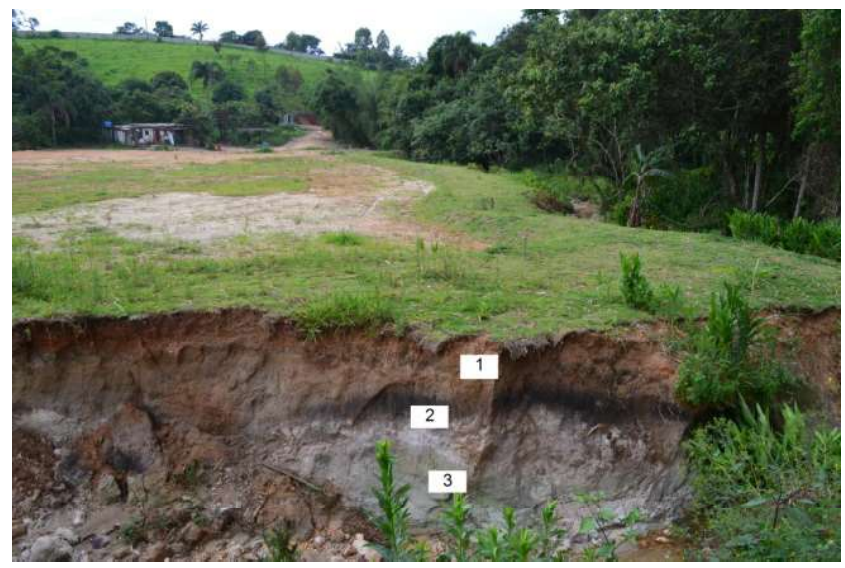

Figura 26 - Perfil estratigráfico observado na ravina (topobacia 0.3): (1) depósito tecnogênico construido (aterro), fácies espólicoacamadada; (2) camada escura provavelmente associada ao acúmulo de material carbonizado; (3) estrato argiloso cinzento, possivelmente antigo aluvião ou solo hidromórfico.

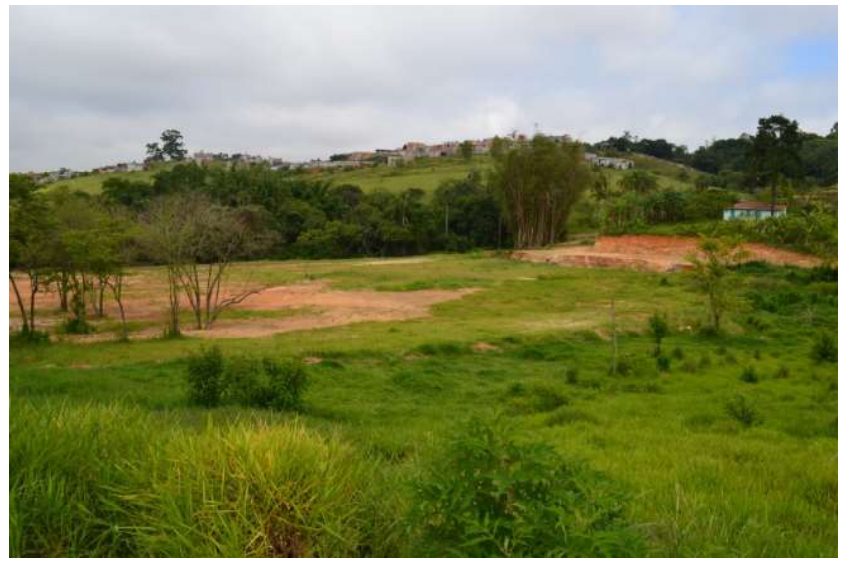

Figura 27 - Terrenos de agradação da planície tecnogênica, topobacia 0.3 .

\subsection{Terrenos complexos}

Os terrenos urbanizados de corte e aterro mapeados, nos setores de ocupação urbana de padrões "B" e "C", correspondem à categoria de landscaped ground proposta pelo Serviço Geológico Britânico (Quadro 1), e resultam de ações de degradação e agradação, em geral de pequena escala porém disseminadas, conjugadas e superpostas, que tornam impossível o mapeamento individualizado na escala de trabalho adotada. Basicamente, são formados na área pelos processos: (1) de corte e aterro (depósitos tecnogênicos espólico-maciços), conjugados para a implantação de moradias em pequenos lotes (Figuras $27 \mathrm{e}$ 28); (2) de lançamento de material geológico mobilizado, entulho e lixo nas encostas, antes ou mesmo depois da ocupação com moradias, cuja remobilização forma depósitos tecnogênicos induzidos de encosta, úrbicomaciços, de tipo coluvial (coberturas remobilizadas)

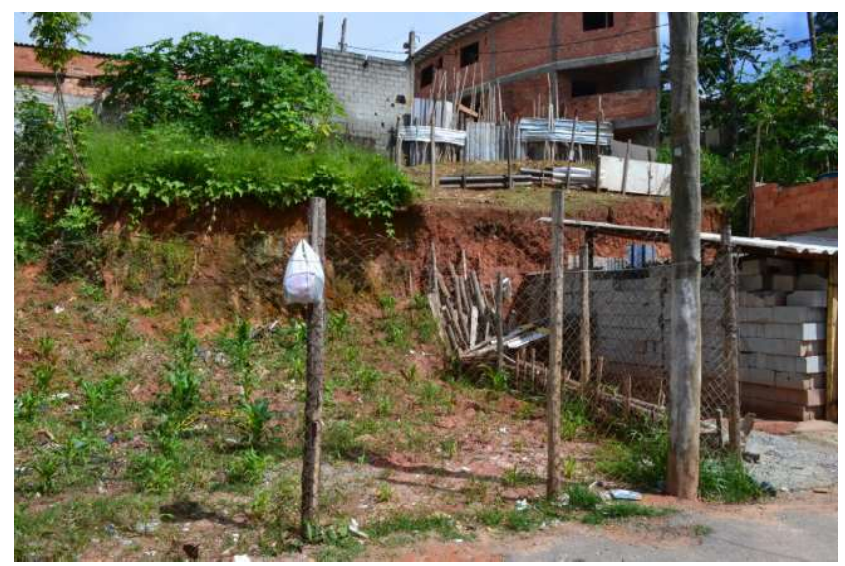

Figura 28 - Típico patamar de corte e aterro individualizado, realizado para implantação de moradia. Padrão de ocupação " $C$ ”, topobacia 0.4.

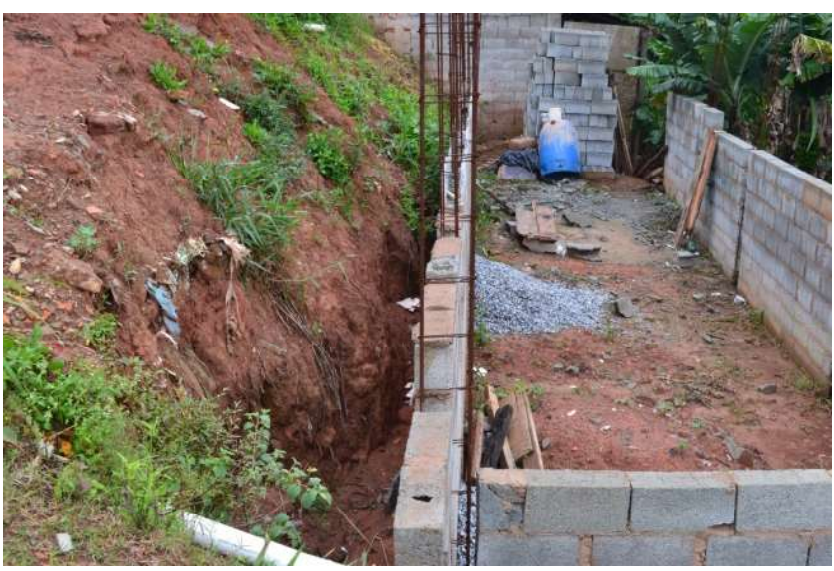

Figura 29 - Patamar de corte e aterro em processo de implantação de moradia, evidenciando a exposição, no corte, do terreno natural na base e de depósito tecnogênico (cobertura remobilizada) no topo. 


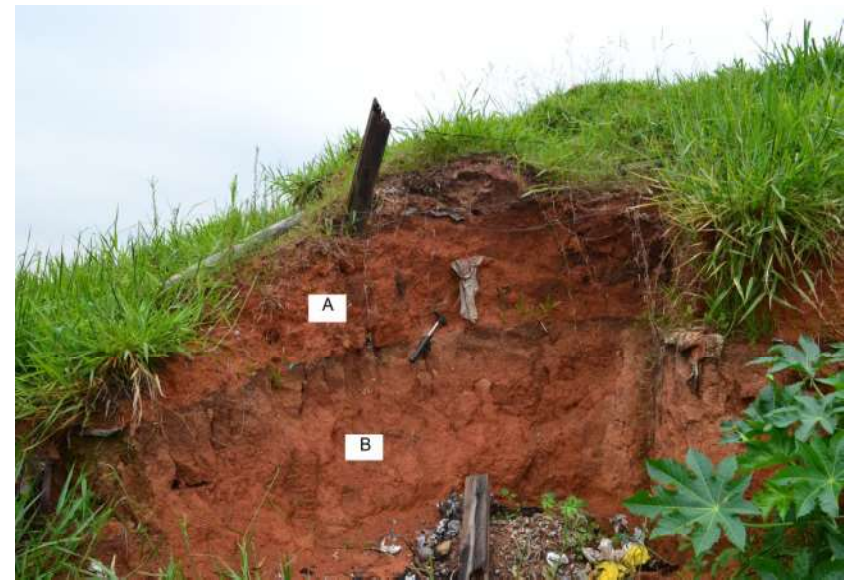

Figura 30 - Setor de encosta (topobacia 0.4) mostrando depósito tecnogênico (cobertura remobilizada) com artefatos $(A)$, sobre o terreno original $(B)$.

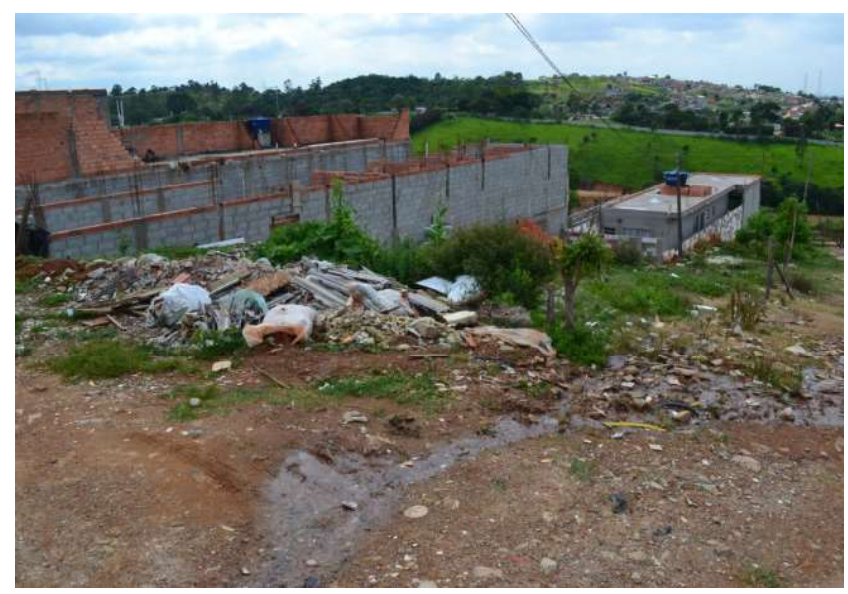

Figura 31 - Setor de encosta de padrão de ocupação em lotes (topobacia 0.2) mostrando a acumulação disseminada de depósitos tecnogênicos úrbicos.

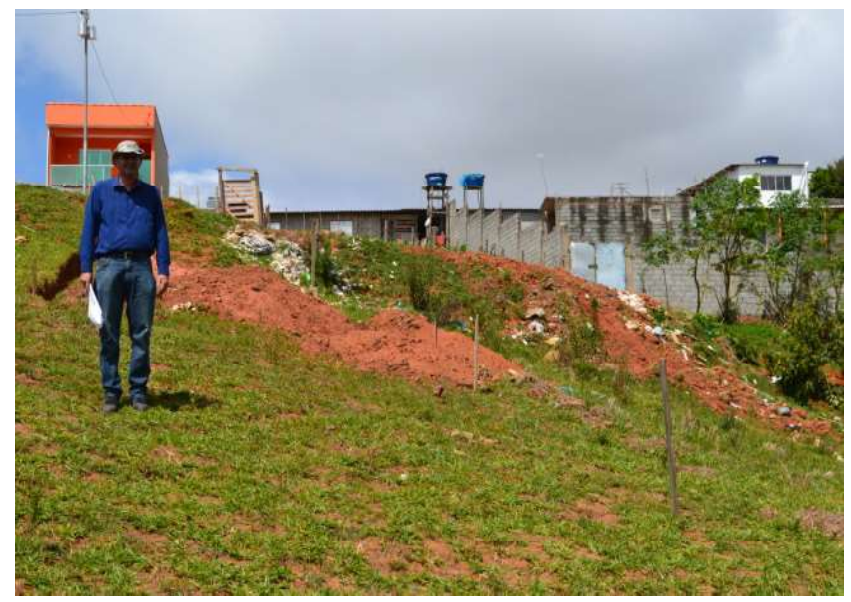

Figura 32 - Setor de encosta de padrão de ocupação em lotes (topobacia 1.2) mostrando depósitos tecnogênicos espólicos.

\section{Configuração da paisagem tecnogênica e do sistema tecnogênico.}

A comparação dos mapas de uso e ocupação do solo, que indica as formas particulares de apropriação do relevo ocorridas na bacia, e de terrenos tecnogênicos, que mostra os resultados geológico-geomorfológicos dessa agência, torna possível a produção de um mapa esquemático (Figura 33) em que a conjugação desses processos e efeitos pode ser caracterizada por um modelo conceitual do sistema tecnogênico da bacia.

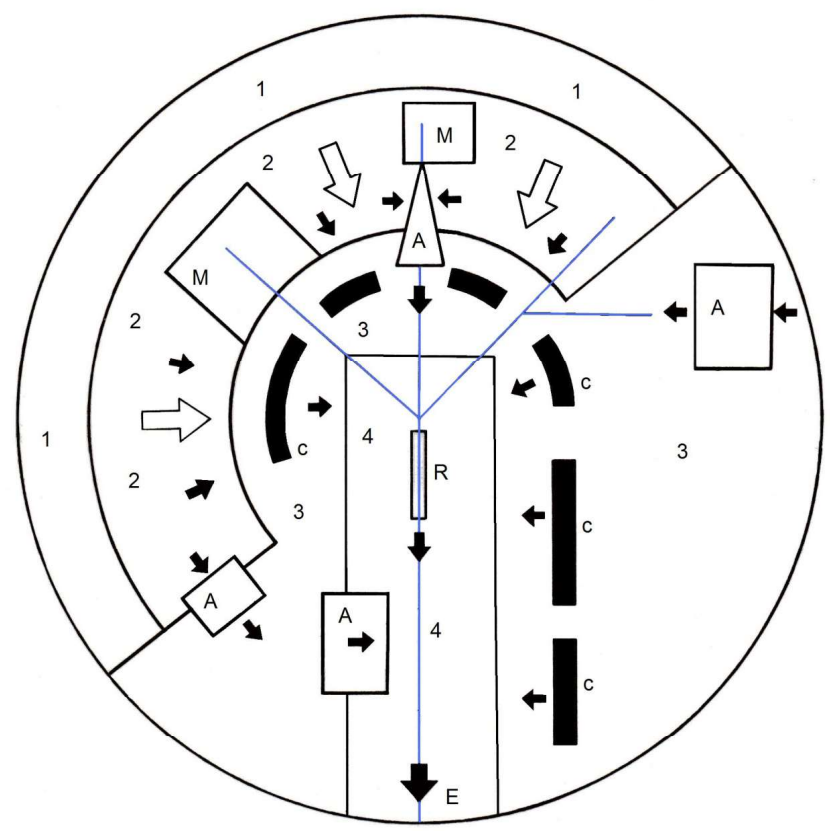

Figura 33 - Esquema conceitual do sistema tecnogênico da sub-bacia estudada, evidenciando os compartimentos de modelado: topos de ocupação urbana regular consolidada (1); segmentos de vertentes de urbanização em expansão (2); vertentes não urbanizadas remanescentes (3); planície tecnogênica não consolidada (4). As setas brancas indicam o sentido de expansão da urbanização, $e$ as pretas o sentido do fluxo do material geológico na bacia. " $M$ " indica os fragmentos de mata remanescentes $e$ " $A$ " os terrenos de agradação (aterros) diferenciados. As áreas pretas " $C$ " são terrenos de degradação (cortes) e " $R$ " é a ravina na planície tecnogênica. Em azul estão representados os cursos d'água, $e$ " $E$ " representa o exutório da bacia.

Esse modelo evidencia, ao mesmo tempo, o conjunto de processos urbanísticos e geológicogeomorfológicos, como o fluxo de material geológico na bacia e a configuração sincrônica da paisagem tecnogênica: a partir dos compartimentos de topo de 
urbanização consolidada do padrão "A" (1), têm-se áreas de expansão urbana em processo (padrões "B" e "C"), formadoras de terrenos atificiais complexos e seus respectivos compartimentos de modelado antropogênico (vertentes modificadas) (2). Em contato direto com estas áreas de expansão urbana, nas porções mais baixas das encostas, verifica-se uma franja de compartimentos de modelado e também de setores de vertentes modificadas marcados por terrenos de degradação, com extensos movimentos de terra (3), que circundam o compartimento de planície tecnogênica (4). Este, como vimos, foi formado por agradação, mas também sofre degradação na forma de processos de remobilização de material geológico por erosão induzida dos depósitos artificiais ou mesmo do substrato original.

Como resultado dessa interação entre apropriação do relevo e tecnogênese, formam-se dois tipos particulares de terrenos artificiais mapeados.

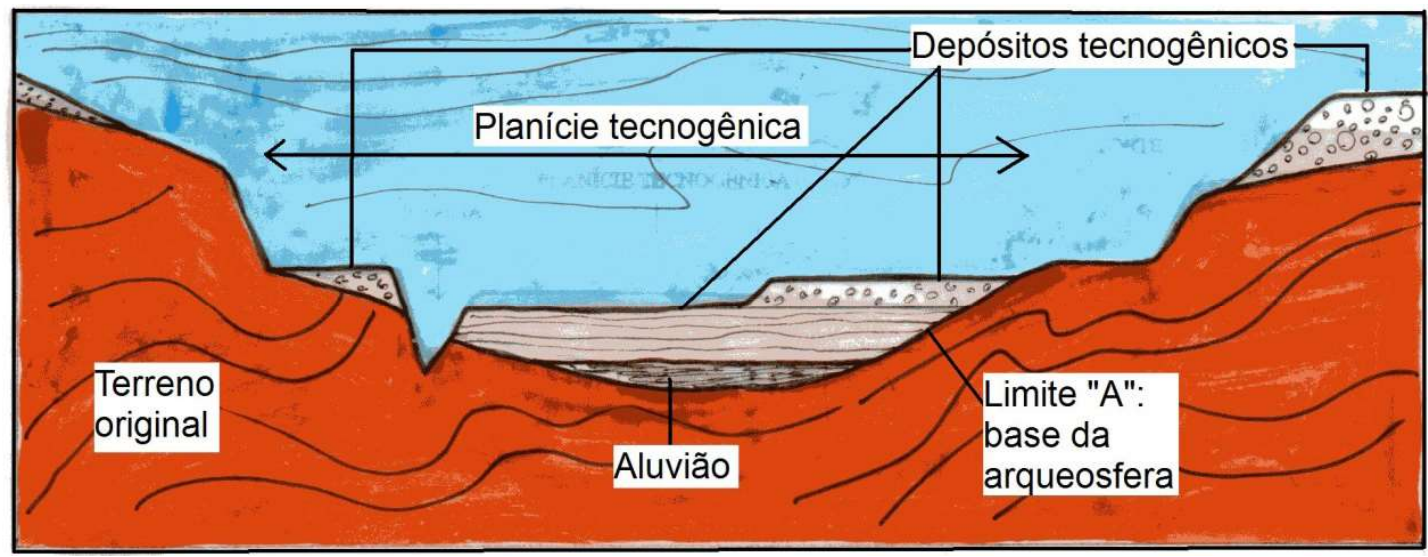

Figura 34 - Esquema conceitual do perfil morfoestratigráfico do fundo de vale de $3^{a}$ ordem (topobacias 0.1, 0.2 e 0.3), onde se evidenciam as feições e estruturas do compartimento da planicie tecnogênica, ladeada por compartimentos de vertentes tecnogenicamente modificadas por terrenos de agradação e degradação. O limite " $A$ " da arqueosfera corresponde à base das camadas tecnogênicas.

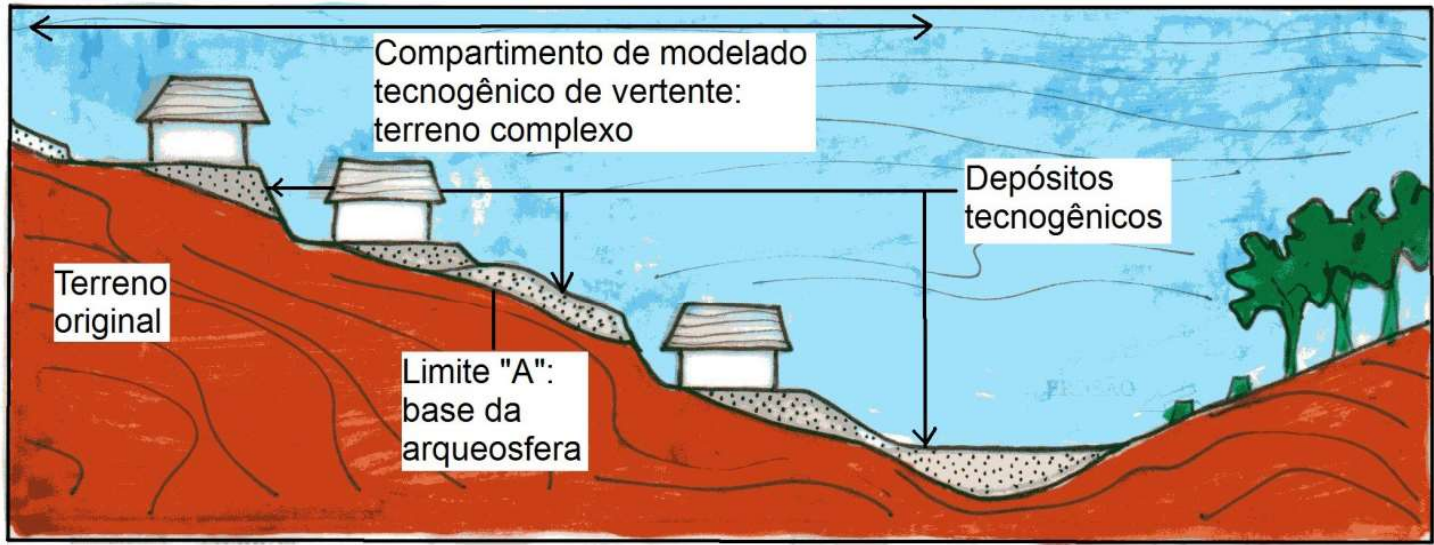

Figura 35 - Esquema conceitual do perfil morfoestratigráfico do vale de $2^{a}$ ordem da topobacia 0.4 , evidenciando o compartimento de vertente tecnogenicamente modificada pela urbanização e o fundo de vale aterrado. O limite " $A$ " da arqueosfera corresponde à base das camadas tecnogênicas.

\section{Síntese da análise geoambiental}

Diferentemente de outras áreas de expansão urbana periférica na RMSP, as quais tiveram seus terrenos artificiais mapeados em detalhe, como o Parque Continental, o Jardim Fortaleza e o bairro do Cabuçu em Guarulhos (OLIVEIRA et al. 2014; VITORINO et al.
2016; SANTOS et al., 2017), os processos tecnogênicos verificados na bacia estudada não resultaram de uma extensa transformação inicial do território a partir de amplos movimentos de terra (terraplanagem), efetuados para implantação de loteamentos, mas de uma sucessão de intervenções relacionadas às particularidades de cada modo de apropriação do relevo e uso do território. 
Como assinalado, a ocupação urbana regular e consolidada do bairro de classe média da área efetuou-se nas porções altas do divisor de águas. A partir dela, na porção N-NW-W da bacia, a ocupação ocorreu e continua ocorrendo, de forma em geral irregular e precária, no sentido vertente abaixo, comprometendo a rede fluvial tanto pela deterioração da qualidade da água devido à ausência de saneamento básico, quanto pela acumulação de sedimentos e detritos no fundo de vale, que começam a ser remobilizados para jusante na bacia do córrego Água Branca e que tendem, portanto, a contribuir para o assoreamento do rio Tietê.

Este impacto do padrão de ocupação das encostas descrito é potencializado em função do tipo de técnica construtiva empregado, que consiste na realização de cortes e aterros conjugados, como é prática geral nas áreas de expansão da região metropolitana (PELOGGIA, 1996, 1998). Tal ação, ao expor o substrato e dispor materiais não compactados, gera taxas de erosão que seriam muito minimizadas caso a ocupação fosse feita por meio outras técnicas, como moradias sustentadas por pilotis, por exemplo, o que é uma opção altamente vantajosa para a urbanização de encostas em geral (RICCA e PELOGGIA, 1997).

No entanto, paradoxalmente, no entanto, tais impactos são mais intensos nos canais de $2^{\mathrm{a}}$ e $3^{\mathrm{a}}$ ordens, uma vez que parte das cabeceiras ainda não é afetada da degradação pela manutenção, ainda que parcial, de fragmentos de mata (topobacias 1.2, 1.3, 1.4, $1.5 \mathrm{e}$ 1.6). Esta situação, no quadro geoambiental analisado, é positiva, uma vez que a implementação de medidas efetivas de proteção dessas áreas poderia garantir a preservação das nascentes, com potencial de uso local para abastecimento da comunidade, ou outros, e de constituir ponto de partida para a recuperação ambiental da área a partir da manutenção de serviços ecossistêmicos básicos (OLIVEIRA et al., 2008).

Tal situação favorável não se verifica na topobacia 1.7, onde a implantação do aterro de bota-fora úrbico afetou seriamente a área da nascente, com o comprometimento do recurso hídrico potencialmente se estendendo aos canais de maior ordem para jusante. Trata-se de uma situação que exige intervenção de mitigação imediata em função da gravidade do impacto ambiental.

\section{Considerações finais: apropriação do relevo e tecnogênese}

Os processos de ocupação do território implicam na criação de terrenos tecnogênicos cujas características e constituições refletem, por um lado, as particularidades socioeconômicas e culturais da sociedade e, por outro, a própria história da apropriação do relevo e das características dos maciços originais.

$\mathrm{Na}$ área estudada neste trabalho verificou-se, quanto ao primeiro aspecto da agência humana, acima citado, a repetição de um padrão de produção do urbano socialmente segregado e injusto, tecnicamente incorreto e ambientalmente desastroso, que potencializa as fragilidades naturais. O resultado geral do processo é a criação de uma paisagem tecnogênica, constituída por terrenos artificiais que modificam o relevo no nível do $6^{\circ}$ táxon (tipos de vertentes) e do $5^{\circ}$ táxon (formas de processos) de Ross (1992), e atestam o início da criação do estrato geológico urbano, ou arqueosfera, na área.

\section{Agradecimentos}

Os autores agradecem à Universidade UNG pelas facilidades disponibilizadas pelo Laboratório de Geoprocessamento, bem como aos criteriosos e proveitosos comentários dos pareceristas.

\section{Referências Bibliográficas e Cartográficas}

ABREU, A.A. Ação antrópica e propriedades morfodinâmicas do relevo na área metropolitana de São Paulo. Orientação, n.7, p.35-38, 1986.

ABREU,A.A. (1992) Do Pátio do Colégio ao Planalto Paulistano: problemas geomorfológicos emergentes do Município de São Paulo. In: Problemas Geológicos e Geotécnicos na Região Metropolitana de São Paulo. ABAS/ABGE/SBG-SP, São Paulo, p.47-54.

AB'SABER, A.N. Geomorfologia do Sítio Urbano de São Paulo. Cotia: Ateliê Editorial, 2007, 349p.

AB'SABER, A.N. O sítio urbano inicial da aglomeração paulistana. Acrópole, ano XXV, n.295-296, p. 205-208, 1963 a.

AB'SABER, A.N. Originalidade do sítio da Cidade de São Paulo. Acrópole, São Paulo, ano XXV, n.295-296, p. 239-246, 1963 b.

ALEXANDROVSKAYA, E.I. e ALEXANDROVSKIY, A.L.. History of the cultural layer in Moscow and accumulation of anthropogenic substances in it. Catena n.41, p. 249-259, 2000.

BARROS, L.H.S. e PELOGGIA, A.U.G. Cartografia geotécnica como fundamento para recuperação de áreas urbanas degradadas: o exemplo do Jardim Eliane, município de São Paulo. In: Congresso Brasileiro de Geologia de Engenharia, 7, 1993, Poços 
de Caldas, Atas... ABGE, São Paulo, 1993, v.2, p.83-91.

BINI, M.; PAPPALARDO, M.; ROSSI, V.; NOTI, V.; AMOROSI, A.; SARTI, G. Deciphering the effects of human activity on urban áreas though morphostratigraphic analysis: the case of Pisa, Northwest Italy. Geoarchaeology 2017 (online): 1-9, 2017. DOI: 10.1002/gea.21619.

BRAGA, E.; PELOGGIA, A.U.G.; OLIVEIRA, A.M.S. Análise de risco geológico em encostas tecnogênicas urbanas: o caso do Jardim Fortaleza (Guarulhos, SP, Brasil). Revista UNG Geociências v.15, n.1, p.27-42, 2016.

BROWN, A.G.; TOOTH, S.; BULLARD, J.E.; THOMAS, D.S.G.; CHIVERRELL, R.C.; PLATER, A.J.; MURTON, J.; THORNDYCRFT, V.R.; TAROLLI, P.; ROSE.J.; WAINWRIGHT, J. DOWNS, P.; AALTO, R.. The geonorphology of the Anthropocene: emergence, status and implications. Earth Surface Processes and Landforms, v.42, n.1, p.71-90, 2017. DOI: $10.1002 /$ esp.3943.

CHRISTOFOLETTI, A. (1980). Geomorfologia. 2.ed. São Paulo: Edgard Blücher, 188p.

CPRM - SERVIÇO GEOLÓGICO DO BRASIL. Mapa Geológico do Estado de São Paulo (1: 750.000). Brasília: Ministério das Minas e Energia, 2005.

EDGEWORTH, M. The relationship between archaeological stratigraphy and artificial ground and its significance in the Anthropocene. In: WATERS, C.N.; ZALASIEWICS, J.A.; WILliAMS, M.; ELLIS, M.A.; SNELLING, A.M. (eds.) A Stratigraphical basis for the Anthropocene. Geological Society Special Publications 395, London, 2014, p. 91-108.

EDGEWORTH, M.; RICHTER, D. DeB.; WATERS, C.; HAFF, P.; NEAL, C.; PRICE, S.J.. Diachronous beginnings of the Anthropocene: the lower bounding surface of anthropogenic deposits. The Anthopocene Review, v.2, n.1, p.33-58, 2015.

EMPLASA - EMPRESA METROPOLITANA DE PLANEJAMENTO. Carta Geológica da Região Metropolitana de São Paulo (1:100.000). São Paulo. Governo do Estado de São Paulo, 1980.

FARIA A.P. \& MARQUES, J.S. O desaparecimento dos pequenos rios brasileiros. Ciência Hoje, v.25, n.146, p.56-61, 1999.

FIGUEIRA, R.M. Evolução dos sistemas tecnogênicos no município de São Paulo. Dissertação (Mestrado em Geologia Sedimentar), Instituto de Geociências, Universidade de São Paulo, 2007, 126p. DOI: 10.11606/D.44.2007.tde-31072007113831 .
FORD, J.R.; PRICE, S.J.; COOPER, H.; WATERS, C.N. An assessment of lithostratigraphy for anthropogenic deposits. In: WATERS, C.N.; ZALASIEWICS, J.A.; WILLIAMS, M.; ELLIS, M.A.; SNELLING, A.M. (eds.) A stratigraphical basis for the Anthropocene. Geological Society Special Publication 395, London, 2014, p.55-89.

GOUVEIA, I.C. M-C. Da originalidade do sítio urbano de São Paulo às formas antrópicas: aplicação da abordagem da Geomorfologia Antropogênica na bacia hidrográfica do rio Tamanduateí, na Região Metropolitana de São Paulo. Tese (Doutorado em Geografia Física), Faculdade de Filosofia, Letras e Ciências Humanas, Universidade de São Paulo, 2010, 363p.

HORTON, R.L. Erosional development of streams and their drainage basins: hydrophysical approach to quantitative morphology. Geol. Soc. America Bulletin v.56, n.3, p. 275$371,1945$.

HUGHES, P.D. Geomorphology and Quaternary stratigraphy: the roles of morpho-, litho-, and allostratigraphy. Geomorphology, n.123, p.189-199, 2010. DOI: 10.1016/j.gomorph.2010.07.025.

IPT - INSTITUTO DE PESQUISAS TECNOLÓGICAS DO ESTADO DE SÃO PAULO. Mapa Geomorfológico do Estado de São Paulo (1:1.000.000). São Paulo: Governo do Estado de São Paulo, 1981.

IPT - INSTITUTO DE PESQUISAS TECNOLÓGICAS DO ESTADO DE SÃO PAULO. Carta Geotécnica do do Estado de São Paulo (1:500.000), Folha São Paulo. São Paulo: Governo do Estado de São Paulo, 1994.

IPT/- INSTITUTO DE PESQUISAS TECNOLÓGICAS DO ESTADO DE SÃO PAULO / CPRM - SERVIÇO GEOLÓGICO DO BRASIL. Carta de suscetibilidade a movimentos gravitacionais de massa e inundações (1:25.000). Folha Itaquaquecetuba - SP. Brasil, Ministério das Minas e Energia, 2013.

JORDAN, H.; HAMILTON, K.; LAWLEY, R.; PRICE, S.J. Antropogenic contribution to the geological and geomorphological record: a case study from Greath Yarmouth, Norfolk, UK. Geomorphology, n.253, p.534-546, 2016. DOI: 10.1016/j.geomorph.2014.07.008.

KAZUO, K. Geologic interpretation of artificial strata in urbanized areas. Journal of Geosciences (Osaka City University), n.44, p.121-135, 2001.

KUTNER, A.S.; BJORNBERG, A.J.S. Contribuição para o conhecimento geológico da bacia de São Paulo: litotipos, notação estratigráfica e feições estruturais relevantes. Engenharia, v.54, n.522, p.65-73, 1997. 
LUZ, R.A. Geomorfologia da planície fluvial do rio Pinheiros entre os bairros de Pinheiros, Butantâ e Cidade Jardim, São Paulo (SP). Dissertação (Mestrado em Geografia Física), Faculdade de Filosofia, Letras e Ciências Humanas, Universidade de São Paulo, São Paulo, 2010, 104p. DOI: 10.11606/D.8.2010. tde-03112010-093445.

LUZ, R.A. Mudanças geomorfológicas na planície fluvial do rio Pinheiros, São Paulo (SP), ao longo do processo de urbanização. Tese (Doutorado em Geografia Física), Faculdade de Filosofia, Letras e Ciências Humanas, Universidade de São Paulo, São Paulo, 2014, 245p. DOI: 10.11606/T.8.2014.tde29062015-152030.

LUZ, R.A.; RODRIGUES, C. Reconstituição geomorfológica de planícies fluviais urbanizadas: o caso do rio Pinheiros, São Paulo -SP. Revista Brasileira de Geomorfologia n. 14, p.47-57, 2013.

LUZ, R.A.; RODRIGUES, C. Anthropogenic changes in urbanised hydromorphological systems inn a humid tropical environment: River Pinheiros, São Paulo, Brazil. Zeitschrift für Geomorphologie, Supplementary Issues, n.59, p.109135, 2015.

MCMILLAN A.A.; POWELL J.H. (1999) BGS Rock Classification Scheme: V4 - Classification of artificial (man-made) ground and natural superficial deposits. British Geological Survey Research Report n. RR 99-04, Nottingham: BGS, 65p.

MIRANDOLA, F.A.; MACEDO, E.S. Proposta de classificação do Tecnógeno para uso no mapeamento de áreas de risco de deslizamento. Quaternary and Environmental Geosciences, v.5, n.1, p.66-81, 2014.

OLIVEIRA A.M.S.; ANDRADE M.R.M.; SATO S.E.; QUEIROZ W.;LACAVA M.A.; SAAD, A.R. Atlas ambiental da região do Cabuçu-Tanque Grande, Guarulhos, SP. Guarulhos: Universidade Guarulhos, 2008, 54p.

OLIVEIRA, A.A.; OLIVEIRA, A.M.S.; ANDRADE, M.R.M. Depósitos tecnogênicos como testemunhos e indicadores de processos geológicos em área urbana degradada em Guarulhos, SP. Quaternary and Environmental Geosciences, v.5, n.1, p.12-27, 2014.

OLIVEIRA S.A.; PEIXOTO, M.N.O; MELLO, E.V. 2015. Lugares de perigo na Cidade do Aço: uma discussão sobre geotecnogênese, vulnerabilidade e risco ambiental em Volta Redonda (RJ). In: ENCONTRO NACIONAL DA ANPEGE, XI, 2015, Presidente Prudente, Anais... 2015, UFGD Editora. ISSN 2175-8875. Disponível em www.enanpege.ggf.br/2015/ anais. Acesso em 25.07.2017.
PELOGGIA, A.U.G. As coberturas remobilizadas: depósitos tecnogênicos de encostas urbanas no município de São Paulo. Solos e Rochas, v.17, n.2, p.120-125, 1994.

PELOGGIA, A.U.G. Delineação e aprofundamento temático da geologia do Tecnógeno do Município de São Paulo. Tese (Doutorado em Ciências), Instituto de Geociências, Universidade de São Paulo, São Paulo, 1996, 262p. DOI: 10.11606/T.44.1997. tde-03102014-100328.

PELOGGIA, A.U.G. A ação do homem como ponto fundamental da geologia do Tecnógeno: proposição teórica básica e discussão acerca do caso do município de São Paulo. Revista Brasileira de Geociências, v.27, n.3, p.257-268, 1997a.

PELOGGIA, A.U.G. A ação geológica do homem no município de São Paulo. Revista Brasileira de Ecologia, n.1, p.10-12, $1997 b$.

PELOGGIA, A.U.G. O homem e o ambiente geológico: geologia, sociedade e ocupação urbana no município de São Paulo. São Paulo: Xamã, 1998, 271p.

PELOGGIA, A.U.G. Sobre a classificação, enquadramento estratigráfico e cartografação dos depósitos tecnogênicos. In: PREFEITURA DO MUNICÍPIO DE SÃO PAULO/SEHAB/ HABI, Estudos de Geotécnica e Geologia Urbana (I), São Paulo, Manual Técnico 3 (GT-GEOTEC), 1999, p.35-50.

PELOGGIA, A.U.G. Ilustrações das consequências geológicas da ação humana no município de São Paulo. In: PREFEITURA DO MUNICÍPIO DE SÃO PAULO/SEHAB/HABI, Estudos de Geotécnica e Geologia Urbana (II), São Paulo, Manual Técnico 5 (GT-GEOTEC), 2000, 12p.

PELOGGIA, A.U.G. A cidade, as vertentes e as várzeas: a transformação do relevo pela ação do homem no município de São Paulo. Revista do Departamento de Geografia, n.16, p.24-31, 2005.

PELOGGIA, A.U.G.; OLIVEIRA A.M.S.; OLIVEIRA A.A.; SILVA E.C.N.; NUNES J.O.R. Technogenic geodiversity: a proposal on the classification os artificial ground. Quaternary and Environmental Geosciences, v.5, n.1, p.28-40, 2014a.

PELOGGIA, A.U.G.; SILVA E.C.N.; NUNES J.O.R. Technogenic landforms: conceptual framework and application to geomorphologic mapping of artificial ground and landscape as transformed by human geological action. Quaternary and Environmental Geosciences, v.5, n.2, p.67-81, 2014 b.

PELOGGIA, A.U.G. Camadas que falam sobre o ser humano, caso encontrem arqueólogos e geólogos que as escutem: rumo a uma arqueogeologia interpretativa dos depósitos tecnogênicos. 
In: ORTEGA, A.M. E PELOGGIA, A.U.G. (orgs.) Entre o Arcaico e o Contemporâneo: ensaios fluindo entre Arqueologia, Psicanálise, Antropologia e Geologia. Iglu Editora, São Paulo, 2015, p.189-221.

PELOGGIA, A.U.G. e ORTEGA, A.M. Sobre a recorrência geohistórica de desastres ambientais no Sudeste do Brasil: uma perspectiva de longa duração. Revista UNG - Geociências, v.15, n.2, p.61-74, 2016.

PELOGGIA, A.U.G. O que produzimos sob nossos pés? Uma revisão comparativa dos conceitos fundamentais referentes a solos e terrenos antropogênicos. Revista UNG - Geociências, v.16, n.1, p.102-127, 2017.

PRADO Jr., C. O fator geográfico na formação e no desenvolvimento da cidade de São Paulo. In: Evolução política do Brasil e outros estudos. 3.ed, Editora Brasiliense, São Paulo, 1961a, p.97-115.

PRADO Jr., C. Contribuição para a geografia urbana da cidade de São Paulo. In: Evolução política do Brasil e outros estudos. 3.ed, Editora Brasiliense, São Paulo, 1961b, p. 117-146.

PRICE S.J.; FORD J.R.; KESSLER H.; COOPER A.; HUMPAGE A. Artificial ground: mapping our impact on the surface of the Earth. Earthwise, n.20, p.30-32, 2004.

PRICE S.J.; FORD J.R.; COOPER A.H.; NEAL C. Human as major geological and geomorphological agents in the Anthropocene: the significance of artificial ground in Great Britain. Phil. Trans. R. Soc. A. n.369, p.1056-1086, 2011.

RICCA Jr., J.; PELOGGIA, A.U.G. Reflexões sobre a arquitetura e as encostas urbanas. Revista Brasileira de Ecologia, n.1, p.167-169, 1997.

RODRIGUES, C. A urbanização da metrópole sob a perspectiva da geomorfologia: tributo a leituras geográficas. In: CARLOS, A.F.A. E OLIVEIRA, A.U.D. Geografias de São Paulo: representação e crise da metrópole.Editora Contexo, São Paulo, 2004, p.89-114.

RODRIGUES, C. Morfologia original e morfologia antropogênica na definição de unidades espaciais de planejamento urbano: exemplo na metrópole paulista. Revista do Departamento de Geografia, n.17, p.101-111, 2005.

RODRIGUES, C. Avaliação do impacto humano da urbanização em sistemas hidro-geomorfológicos: desenvolvimento e aplicação de metodologia na Grande São Paulo. Revista do Departamento de Geografia, n.20, p.111-125, 2010.

RODRIGUES, C. Atributos ambientais no ordenamento territorial urbano: o exemplo das planícies fluviais na metrópole de São Paulo. Geousp - Espaço e Tempo, v.19, n.2, p.325-348, 2015.

ROLNIK, R.; KOWARIK, L.; SOMEKH, N. São Paulo: crise e mudança. São Paulo: PMSP/SMP: Brasiliense, 1991, 215p.

ROSEMBAUM M.S.; McMILLAN A.A.; POWELL J.H.; COOPER A.H.; CULSHAW M.G.; NORTHMORE K.J. Classification of artificial (man-made) ground. Engineering Geology, v.69, n.3-4, p.399-409, 2003.

ROSS, J.L.S. O registro cartográfico dos fatos geomórficos e a questão da taxonomia do relevo. Revista do Departamento de Geografia, n.6, p.17-29, 1992.

ROSS, J.L.S. Geomorfologia aplicada aos EIAs-RIMAs. In: GUERRA, A.J.T. E CUNHA, S.B. (orgs.) Geomorfologia e meio ambiente. Editora Bertrand Brasil, Rio de Janeiro, 1996, p.291-336.

ROSS,J.L.S.; MOROZ, I.C. Mapa Geomorfológico do Estado de São Paulo Escala 1:500.000. São Paulo, FFLCH-USP/IPT, 1997 (2 folhas).

SANTOS, E.Q.G.; FERREIRA, A.T.S.; PELOGGIA, A.U.G.; SAAD, A.R.; OLIVEIRA, A.M.S.; SANTOS, M.S.T. Terrenos e processos tecnogênicos na área de proteção ambiental Cabuçu-Tanque Grande, Guarulhos (SP): análise, mapeamento e quantificação. Revista Brasileira de Geomorfologia v.18, n.4, p.825-839.

SCHEIDEGGER, A.E. On the topology of river nets. Water Resources Research v.3, n.1, p. 103-106, 1967.

SCHREVE, R.L. Statistical law of stream numbers. Journal of Geology v.74, n.1, p. 17-37, 1966.

SCHREVE, R.L. Infinite topologically random channel networks. Journal of Geology v.75, n.2, p.178-186, 1967.

SHERLOCK, R. Man as a geological agent: an account on his action on inanimate nature. London: H.F. \& G. Witherby, 1922, 372p.

STRAHLER, A.N. Geología Física. Barcelona: Omega, 1992, $629 \mathrm{p}$.

SUESS, E. Der Boden der Stadt Wien. Vienna: Wilhelm Braumüller, 1862, 326p.

VITORINO, J.C.; ANDRADE, M.R.M.; PELOGGIA, A.U.G.; SAAD, A.R.; OLIVEIRA, A.M.S. Terrenos tecnogênicos do Jardim Fortaleza, bacia hidrográfica do córrego do Entulho, Guarulhos (SP): mapeamento geológico, estratigrafia, geomorfologia e arqueologia da paisagem. Revista UNG Geociências, v.15, n.2, p.33-60, 2016. 
WATERS, C.N.; PRICE, S.J.; DAVIES, J.; TYE, A.M.; BROWN, S.E.; SCHOFIELD, D.S. Urban geology of Swansea - Neath - Port-Talbot. In: BASSET, M.G.; DEISLER, V.K.; NICHOL, D. (eds.) Urban Geology in Wales, v.2, National Museum of Wales, Geological series 24, 2005, 7-22.

WATERS, C.N. Artificial ground. In: BOBROWSKY, P.T;
MARKER, B. (eds.) Encyclopaedia of Engineering Geology. Cham: Springer International Publishing, 2018, p.1-15.

ZALASIEWICZ, J. The Earth After Us: what legacy will humans leave in the rocks? Oxford: Oxford University Press, 2008, 251p. 